\title{
Sonochemical Synthesis of a Two-Dimensional Supramolecular Polymer with Nanoporous Morphology, Linear Thallophilic and Covalent Hydrogen Bonding Interactions
}

\author{
Sahar Yusefi ${ }^{1}$, Kamran Akhbari ${ }^{1, *}$, Jonathan White ${ }^{2}$, Anukorn Phuruangrat ${ }^{3}$ \\ ${ }^{1}$ School of Chemistry, College of Science, University of Tehran, Tehran, Iran. \\ P.O. Box 14155-6455; Tel.: +98 21 61113734; fax: +98 21 66495291. E-mail address: \\ akhbari.k@khayam.ut.ac.ir (K. Akhbari) \\ ${ }^{2}$ School of Chemistry and Bio21 Institute, The University of Melbourne, VIC 3010, Australia \\ ${ }^{3}$ Department of Materials Science and Technology, Faculty of Science, Prince of Songkla \\ University, Hat Yai, Songkhla, Thailand.
}

\begin{abstract}
A new thallium-based supramolecular polymer $\left[\mathrm{Tl}\left(\mu_{3}-3-\mathrm{HClb}\right)\left(\mu_{3}-3-\mathrm{Clb}\right)\right]_{\mathrm{n}}(\mathbf{1}),(3-\mathrm{HClb}=3-$ chloroperbenzoic acid), has been synthesized and structurally characterized by single crystal Xray crystallography. It has a two-dimensional structure with linear thallophilic and covalent hydrogen bonding interactions. In order to evaluate the effects of concentration, ultrasonic irradiation and type of the solvents on structure, morphology and thermal behavior of $\mathbf{1}$, some experiments were designed and eight samples of $\mathbf{1}$ were synthesized under different conditions. These samples were characterized by IR spectroscopy, thermogravimetric and differential thermal analyses (TG-DTA), X-ray powder diffraction (XRD) and Scanning Electron Microscopy (SEM).
\end{abstract}

Keywords: Thallium(I); Supramolecular Polymer; Hydrogen Bonding; Thallophillic; Nano; Sonochemical.

This is the author manuscript accepted for publication and has undergone full peer review but has not been through the copyediting, typesetting, pagination and proofreading process, which may lead to differences between this version and the Version of Record. Please cite this article as doi: $10.1002 /$ aoc. 4747

This article is protected by copyright. All rights reserved. 


\section{Introduction}

During past years, supramolecular compounds have monopolized the attention of researchers and still, this is a growing field. Inorganic-organic framework structures have different structures and polyfunctional organic molecules bridge the metal centers. ${ }^{1}$ Syntheses and design of coordination supramolecular compounds, which bring in a major numeral of interactions and self-assembly of organic ligands with functional groups and metal ions with special directionality, has produced admirable advance within the field of coordination supramolecular chemistry. ${ }^{2-6}$ The synthesis of these supramolecular polymers gives us the opportunity to react to a variety of conditions such as solvent, $\mathrm{pH}$ value, temperature, template, and the ratio of the reactants. The factors that influence the crystal formation can be density, melting point of the reaction solvents with different viscosity. $^{7,8}$ The chemistry and coordination treatment of thallium(I) ion is very unique and attractive. The formation of polymers with thallium(I) is disproportionately sparse when compared with those of other metals. Thallium(I) coordination polymers is a progressively active area because of the presence of a $6 \mathrm{~S}^{2}$ electron configuration. Configuration is stereoactivity of the valence shell lone electron pair and conforming to directed ligands classify as holodirected and hemidirected. ${ }^{9}$ Other secondary interactions such as Tl...Tl, Tl...C, Tl...H exist in thallium(I) supramolecular chemistry which identifies $\mathrm{Tl}(\mathrm{I})$ supramolecular polymers from other supramolecular compounds. ${ }^{10,11}$ Specially thallium(I) compounds are similar in structure and chemical properties to potassium. ${ }^{12,13}$ Much progress has been made using simple systems composed of covalent or strong hydrogen bond with peripheral hydrogen bonding substituents. ${ }^{14,15}$ The new types of hydrogen bonds (HB) in organometallic chemistry can be divided into three types according to the site of coordination and the role of the organometallic species in a hydrogen bonded pair. ${ }^{16}$ Hydrogen bonds range from the very strong, comparable with covalent bonds, to the very weak, comparable with Vander Waals forces. Most hydrogen bonds are weak attractions with a binding strength about one-tenth of that of a normal covalent bond. ${ }^{17,18}$ A variety of methods such as Sol-Gel, microwave and sonochemical exist for synthesizing nano coordination polymers. ${ }^{19-27}$ Sonochemical methods have been successfully 
used to the preparation of diverse nanostructured materials including coordination polymers, metal-organic frameworks, metal carbides and metal oxides at room temperature, ambient pressure with short reaction time. ${ }^{28-30}$ Sonochemistry concludes its success in creating nanostructured materials principally from acoustic cavitation; the formation, growth, and implosive collapse of bubbles in a liquid. Bubble collapse induced by cavitation produces intense local heating, high pressures and very short lifetimes. ${ }^{31,32}$ Ultrasonic method, with benefit such as cost-effectively and being environmentally friendly, is suitable for synthesizing of nanoscale coordination supramolecular compounds. ${ }^{33}$ Herein, we wish to report a new thallium-based coordination polymer, $\left[\mathrm{Tl}\left(\mu_{3}-3-\mathrm{HClb}\right)\left(\mu_{3}-3-\mathrm{Clb}\right)\right]_{\mathrm{n}}$ (1) with linear thallophilic and covalent hydrogen bonding interactions, which was characterized by IR spectroscopy and single-crystal $\mathrm{X}$-ray diffraction. Prior to this study, some coordination polymers with metallophilic interaction such as $\left[\mathrm{Na}\left(\mu_{2} \text {-Hdcpa }\right)\left(\mu_{3} \text {-dcpa }\right)\right]_{n},(\text { Hdcpa }=2,4 \text {-dichlorophenoxyacetic acid })^{7},\left[\mathrm{Tl}\left(\mu_{3}-\mathrm{HTA}\right)\right]_{\mathrm{n}}$, $\left(\mathrm{H}_{2} \mathrm{TA}=\text { terephetalic acid }\right)^{34}$ and $\left\{[\mathrm{Ag}(1-\text { methylhydantoin })] \cdot 0.5 \mathrm{H}_{2} \mathrm{O}\right\}_{n}{ }^{35}$ were reported. Moreover, the effects of ultrasonic irradiation, the concentration of initial reagents and types of solvents on the formation of compound 1 nanostructure were investigated.

\section{Experimental}

\subsection{Materials and Physical Techniques}

All reagents and solvents for the synthesis and analysis were commercially available and were used as received. The molecular structure plots were prepared using Mercury. ${ }^{36}$ PARSONIC $15 \mathrm{~S}$ ultrasonic bath (with the frequency $28 \mathrm{KHz}$ ) was used for the ultrasonic irradiation. Melting points were measured on an Electrothermal 9100 apparatus and are uncorrected. IR spectra were recorded using an Equinox 55 FT-IR spectrometer (Bruker, Bremen, Germany) in ATR form, in the range of $400-4000 \mathrm{~cm}^{-1}$ with $4.0 \mathrm{~cm}^{-1}$ resolution and the 16 scan's numbers. Intensity data for $\left[\mathrm{Tl}\left(\mu_{3}-3-\mathrm{HClb}\right)\left(\mu_{3}-3-\mathrm{Clb}\right)\right]_{\mathrm{n}}$ (1) was collected with an Oxford Diffraction SuperNova CCD diffractometer using $\mathrm{Mo}-\mathrm{K}_{\alpha}$ radiation, the temperature during all data collections was maintained 
at 130.01(10) $\mathrm{K}$ using an Oxford Cryosystems cooling device. The structures were solved by direct methods and difference Fourier synthesis. ${ }^{37}$ Thermal ellipsoid plots were generated using the program ORTEP- $3 .{ }^{38}$ within the WINGX suite of programs. ${ }^{39}$ The thermal behavior was measured with a PL-STA 1500 apparatus between 20 and $800{ }^{\circ} \mathrm{C}$, with a heating rate of 5 ${ }^{\circ} \mathrm{C}$.min- ${ }^{1}$, under a nitrogen atmosphere. X-ray powder diffraction (XRD) measurements were performed using an X'pert diffractometer manufactured by Philips with monochromatized $\mathrm{CuK}_{\alpha}$ radiation $(\lambda=1.54056 \AA$ ) with step-size of 0.01671 (degree). The X-ray source was operated under voltage and current of $40 \mathrm{kV}$ and $30 \mathrm{~mA}$, respectively. Bragg-Brentano was used as a source-detector geometry with scintillation detector. Additional attachments or peripheral equipment such as anti-scatter slit $\left(1^{\circ}\right)$, divergence slit $\left(1^{\circ}\right)$, monochromator and soller slit $(0.04$ rad) were also used in this diffractometer. The samples were prepared as fine powders on silicon based material. Simulated XRD powder patterns based on single crystal data were prepared using the Mercury software. The samples were characterized by a scanning electron microscope (Philips XL 30) with gold coating.

\subsection{Synthesis of $\left[\mathrm{Tl}\left(\mu_{3}-3-\mathrm{HClb}\right)\left(\mu_{3}-3-\mathrm{Clb}\right)\right]_{\mathrm{n}}(1)$ and preparation of its single crystals.}

$1 \mathrm{mmol}(0.172 \mathrm{~g}$ ) 3-chloroperbenzoic acid was dissolved in $15 \mathrm{~mL} \mathrm{MeCN}$ was mixed and stirred with a solution of $1 \mathrm{mmol}(0.057 \mathrm{~g}) \mathrm{KOH}$ in $10 \mathrm{~mL} \mathrm{H}_{2} \mathrm{O}$ at $100{ }^{\circ} \mathrm{C}$ for an hour. Then a solution of $1 \mathrm{mmol}(0.266 \mathrm{~g}) \mathrm{TlNO}_{3}$ in $5 \mathrm{~mL} \mathrm{H}_{2} \mathrm{O}$ was added to the mixture in a dropwise manner and heated at $100{ }^{\circ} \mathrm{C}$ for an hour. After filtering, it was allowed to evaporate for several days and then suitable white crystals were obtained. d.p. $=292^{\circ} \mathrm{C}$.

\subsection{Synthesis of $\left[\mathrm{Tl}\left(\mu_{3}-3-\mathrm{HClb}\right)\left(\mu_{3}-3-\mathrm{Clb}\right)\right]_{\mathbf{n}}(1)$ as bulk samples.}

To synthesis the bulk sample of $\left[\mathrm{Tl}\left(\mu_{3}-3-\mathrm{HClb}\right)\left(\mu_{3}-3-\mathrm{Clb}\right)\right]_{\mathrm{n}}(\mathbf{1})$, (Sample S1, Table 3), a water solution of $3-\mathrm{HClb}(10 \mathrm{~mL}, 0.025 \mathrm{M})$ was mixed and stirred with $0.25 \mathrm{mmol} \mathrm{KOH}(0.015 \mathrm{~g})$ for an hour, then a $0.025 \mathrm{M}$ solution of $\mathrm{TlNO}_{3}(10 \mathrm{~mL})$ was added to the mixture and was stirred and 
heated until a white powder of compound 1 was formed. d.p. $=294^{\circ} \mathrm{C}$, Yield: $0.055 \mathrm{~g}(85.3 \%$ based on final product).

Three other samples were synthesized according to the above procedures but with some differences in concentration of initial reagents and the type of solvents.

For sample S3 (Table 3): with $0.025 \mathrm{M}$ concentration of initial reagents and mixture of $\mathrm{MeCN}: \mathrm{H}_{2} \mathrm{O}$ (7:3) solvent. d.p. $=290{ }^{\circ} \mathrm{C}$, Yield: $0.060 \mathrm{~g}$ (93.0\% based on final product).

For sample S5 (Table 3): with $0.1 \mathrm{M}$ concentration of initial reagents and $\mathrm{H}_{2} \mathrm{O}$ solvent. d.p. = $287^{\circ} \mathrm{C}$, Yield: $0.215 \mathrm{~g}(83.3 \%$ based on final product).

For sample S7 (Table 3): with $0.1 \mathrm{M}$ concentration of initial reagents and mixture of $\mathrm{MeCN}: \mathrm{H}_{2} \mathrm{O}$ (7:3) solvent. d.p. $=294{ }^{\circ} \mathrm{C}$, Yield: $0.225 \mathrm{~g}(87.2 \%$ based on final product $)$.

\subsection{Sonochemical synthesis of $\left[\mathrm{Tl}\left(\mu_{3}-3-\mathrm{HClb}\right)\left(\mu_{3}-3-\mathrm{Clb}\right)\right]_{\mathrm{n}}(\mathbf{1})$.}

To synthesis $\left[\mathrm{Tl}\left(\mu_{3}-3-\mathrm{HClb}\right)\left(\mu_{3}-3-\mathrm{Clb}\right)\right]_{\mathrm{n}}(\mathbf{1})$, (Sample S2, Table 3), with sonochemical process, we used ultrasonic bath with 0.025:0.025:0.025 M concentrations $(10 \mathrm{~mL})$ of initial reagents (3$\left.\mathrm{HClb}: \mathrm{KOH}: \mathrm{TlNO}_{3}\right)$ and the power of $28 \mathrm{KHz}$. To the solution of 3- $\mathrm{HClb}$ and $\mathrm{KOH}$ in $\mathrm{H}_{2} \mathrm{O}(10$ $\mathrm{mL})$, a solution of $\mathrm{TlNO}_{3}$ in $\mathrm{H}_{2} \mathrm{O}(10 \mathrm{~mL})$ was added in a dropwise manner under the ultrasonic irradiation until a white powder of compound 1 was formed. d.p. $=283^{\circ} \mathrm{C}$, Yield: $0.056 \mathrm{~g}(87.3 \%$ based on final product).

Three other samples were synthesized according to the above procedures but with some differences in concentration of initial reagents and the type of solvents.

For sample S4 (Table 3): with $0.025 \mathrm{M}$ concentration of initial reagents and mixture of MeCN: $\mathrm{H}_{2} \mathrm{O}$ (7:3) solvent. d.p. $=281{ }^{\circ} \mathrm{C}$, Yield: $0.061 \mathrm{~g}$ (94.3\% based on final product).

For sample S6 (Table 3): with $0.1 \mathrm{M}$ concentration of initial reagents and $\mathrm{H}_{2} \mathrm{O}$ solvent. d.p. = $287^{\circ} \mathrm{C}$, Yield: $0.207 \mathrm{~g}(80.3 \%$ based on final product).

For sample S8 (Table 3): with $0.1 \mathrm{M}$ concentration of initial reagents and mixture of $\mathrm{MeCN}: \mathrm{H}_{2} \mathrm{O}$ (7:3) solvent. d.p. $=294{ }^{\circ} \mathrm{C}$, Yield: $0.230 \mathrm{~g}(89.2 \%$ based on final product $)$. 


\section{Result and discussion.}

The reaction between 3-chloroperbenzoic acid and $\mathrm{TlNO}_{3}$ resulted in the formation of crystalline material (Table 1) with the general formula of $\left[\mathrm{Tl}\left(\mu_{3}-3-\mathrm{HClb}\right)\left(\mu_{3}-3-\mathrm{Clb}\right)\right]_{\mathrm{n}}(\mathbf{1})$. Figure 1a shows that $3-\mathrm{HClb}$ did not deprotonate completely in $\mathbf{1}$. The carbonyl oxygen $\mathrm{O} 2$ is coordinated to two different $\mathrm{Tl}$ ions (Figures $1 \mathrm{~b}$ and 2a), while $\mathrm{O} 1$ is bonded to one $\mathrm{Tl}$ (Figures $1 \mathrm{~b}$ and $2 \mathrm{a}$ ) and

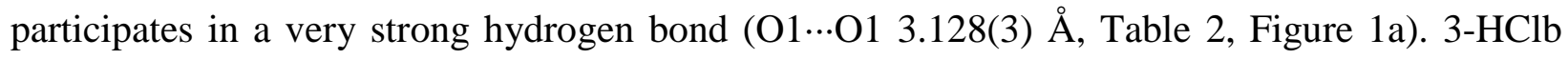
and $3-\mathrm{Clb}^{-}$are bridging between three $\mathrm{Tl}$ ions and can be considered as tridentate ligand (Figure 2a). The $\mathrm{Tl}$ ion in $\mathbf{1}$ has $\mathbf{T l O}_{6}$ coordination sphere (Figure $\mathbf{1 b}$ ). Compound $\mathbf{1}$ is a two-dimensional coordination polymer (Figure 2a) with lozenge framework along the crystallographic $c$ axis (Figures $2 \mathrm{~b}$ and S1 in the SI) and has linear thallophilic bonds (Figure 2c) with distance of $3.7780(8) \AA$, which is lower than the sum of the vander Waals radii of two $\mathrm{Tl}$ atoms ${ }^{40}$ (4.40 ̊). A search about reported values in literatures shows that $\mathrm{Tl} \cdots \mathrm{Tl}$ distances in poly[ $(\mu$-benzene-1,4dithiolato)dithallium], $\mathrm{Tl}_{2}\left(\mathrm{SC}_{6} \mathrm{H}_{4} \mathrm{~S}\right)$ are equal to 3.49 and $3.58 \AA$ and in poly[$[(\mu$-benzene-1,4diselenolato)dithallium], $\mathrm{Tl}_{2}\left(\mathrm{SeC}_{6} \mathrm{H}_{4} \mathrm{Se}\right)$, are equal to 3.54 and $3.63 \AA{ }^{41}$ Also in $[\mathrm{Tl}(\mathrm{L})]_{\infty},(\mathrm{L}=$ (N-benzyl-N- methylpyridyl)dithiocarbamate(L1), bis(N-methylpyridyl)dithiocarbamate(L2), (N- methylpiperonyl-N-methylpyridyl)dithiocarbamate(L3) and (N-ferrocenyl-N-methylpyridyl) dithiocarbamate(L4) Tl $\cdots \mathrm{Tl}$ distances are equal to $3.771 \AA$ and $3.817 \AA$ and $3.763 \AA$ and 3.735 $\AA$, respectively. ${ }^{42} \quad$ catena-[Bis $\left(\mu_{3}\right.$-salicylato $)$ dithallium(I)], catena-[Bis $\left(\mu_{3}\right.$-orthoaminosalicylato)dithallium(I)], catena-[(3,5-Dimethoxybenzoato)thallium(I)] have $\mathrm{Tl} \ldots \mathrm{Tl}$ separations of 4.213(1) $\AA, 4.129 \AA$ and 4.1669(8) $\AA$, respectively. ${ }^{43}\left[\mathrm{Tl}_{4}\left(\mu_{3}-4-\mathrm{BN}\right)_{4}\right]_{\mathrm{n}},(4-\mathrm{HBN}=$ 4-hydroxy benzonitrile), has $\mathrm{Tl} \cdots \mathrm{Tl}$ distance of $3.833 \AA$ and $4.510 \AA \AA^{44} \mathrm{Tl}-\mathrm{Tl}$ distance in

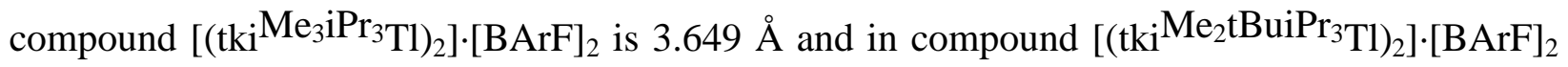
is $3.7862 \AA\left([\mathrm{BArF}]=\left[\left\{3,5-\left(\mathrm{CF}_{3}\right)_{2} \mathrm{C}_{6} \mathrm{H}_{3}\right\}_{4} \mathrm{~B}\right]\right), \beta$-triketimine $=$ tki, tki $\mathrm{Me}_{3} \mathrm{Prr}_{3}=\mathrm{HC}\{\mathrm{MeCN}(2-$ $\left.\left.\left.\mathrm{iPrC}_{6} \mathrm{H}_{5}\right)_{3}\right\} ; \mathrm{tki} \mathrm{Me}_{2} \mathrm{tBuiPr}_{3}=\mathrm{HC}\left\{\mathrm{MeCN}\left(2-\mathrm{iPrC}_{6} \mathrm{H}_{5}\right)\right\}_{2}\left\{\operatorname{tBuCN}\left(2-\mathrm{iPrC}_{6} \mathrm{H}_{5}\right)\right\}\right) .{ }^{45}$ Also Compounds $[\mathrm{Tl}(\text { mchdtc })]_{2}$ and $[\mathrm{Tl}(\text { echdtc })]_{2}$ (mchdtc $=$ methylcyclohexyldithiocarbamate and echdtc $=$ ethylcyclohexyldithiocarbamate) have the $\mathrm{Tl}$...Tl distances of $3.626 \AA$ and 3.658(1) $\AA$ 
respectively. ${ }^{46}$ Finally heterobimetallic species of $\left[\mathrm{Tl}_{2} \mathrm{Cu}\left(\mathrm{OAr}^{\mathrm{F}}\right)_{4}\right]$ and $\left[\mathrm{Tl}_{2} \mathrm{Cu}(\mathrm{OAr})_{4}\right]$ have Tl...Tl contacts of 3.86 and $3.564 \AA$, respectively. ${ }^{47}$ Thus $\mathrm{TlO}_{6} \mathrm{Tl}_{2}$ coordination sphere can be considered around $\mathrm{Tl}(\mathrm{I})$ in $\mathbf{1}$. Against to those observed in thallium(I) compounds, ${ }^{9-11,48-54}$ in compound $\mathbf{1}$, the lone pair of $\mathrm{Tl}(\mathrm{I})$ is 'inactive' in the solid-state and the arrangement of O-atoms do not suggest a gap or hole in coordination geometry around the Tl(I) coordination sphere (Figure 1b). Our search also showed that $\mathrm{Tl}$ in compound 2 did not involve in $\mathrm{Tl} \cdots \mathrm{C}$ and $\mathrm{Tl} \cdots \mathrm{H}$ interactions. This type of $\mathrm{Tl} \ldots \mathrm{Tl}$ and covalent hydrogen bonds are scarce in the literature. Surprisingly, the structure of $\mathbf{1}$ is very similar to $\left[\mathrm{Tl}\left(\mu_{3}-\mathrm{HTA}\right)\right]_{\mathrm{n}}(\mathbf{2}),\left(\mathrm{H}_{2} \mathrm{TA}=\right.$ terephetalic acid), which was reported previously. ${ }^{34}$

In order to evaluate the effects of concentration, ultrasonic irradiation and types of the solvent on the morphology of compound $\mathbf{1}$, we designed some experiments and synthesized eight samples of $\mathbf{1}$ under different conditions (Table 3).

Figure 3 shows the FT-IR spectra of compound 1 single crystal and other eight samples prepared in powder form. The FT-IR spectra of the powder samples (Figure 3b-i) are similar to the crystal sample (Figure 3a). All of them show characteristic absorption bands for the 3$\mathrm{HClb}, 3-\mathrm{Clb}^{-}$ligand. The absorption band with variable intensity in the frequency range 1290$1440 \mathrm{~cm}^{-1}$ corresponds to $\mathrm{C} \quad-O$ ond joup and ring vibrations of the aromatic ring in 3-HClb,3-Clb ligand. The absorption bands in the frequency range of 1440 and $1580 \mathrm{~cm}^{-1}$ attributed to $\mathrm{C}=\mathrm{O}$ bonds in $-\mathrm{COOH}$ group of $3-\mathrm{HClb}, 3-\mathrm{Clb}^{-}$. A weak broadband around $3250-$ $3650 \mathrm{~cm}^{-1}$ was observed which indicated the existence of strong hydrogen bonding interaction in 1. A comparison between simulated XRD pattern from single crystal X-ray data of $\mathbf{1}$ (Figure 4a) and other eight samples prepared in powder form (Figure 4b-i), shows acceptable matches with slight differences in $2 \theta$ between the simulated from single-crystal X-ray data pattern (Figure $4 a$ ) and those from the experimental powder X-ray diffraction patterns of eight samples (Figure $4 \mathrm{~b}$ i). Thus the prepared eight samples have the same structure as $\mathbf{1}$. The morphology and structure of the eight samples (Table 3) were investigated by Scanning Electron Microscopy (SEM). Figure 5a,b indicates the original morphology of S1 sample. Nanoflower of 1 composed from 
nanorods and nanosheets were obtained with $0.025 \mathrm{M}$ concentration of initial reagents in $\mathrm{H}_{2} \mathrm{O}$ without ultrasonic irradiation. Figure 5c,d indicates the original morphology of S2 sample. Agglomerated nanosheets of 1 were obtained with $0.025 \mathrm{M}$ concentration of initial reagents in $\mathrm{H}_{2} \mathrm{O}$ under ultrasonic irradiation. Figure 6a,b indicates the original morphology of S3 sample. Spongy microstructure composed from nanorods and nanosheets of $\mathbf{1}$ were formed in 7:3 mixture of $\mathrm{MeCN}: \mathrm{H}_{2} \mathrm{O}$ with $0.025 \mathrm{M}$ concentration of initial reagents without ultrasonic irradiation. Figure 6c-e indicates the original morphology of S4 sample. Nanoporous microcubes composed from nanoparticles of $\mathbf{1}$ were formed in 7:3 mixture of $\mathrm{MeCN}: \mathrm{H}_{2} \mathrm{O}$ with $0.025 \mathrm{M}$ concentration of initial reagents under ultrasonic irradiation. Figure 7a-c indicates the original morphology of S5 sample. Nanoporous microrods of 1 were obtained with $0.1 \mathrm{M}$ concentration of initial reagents in $\mathrm{H}_{2} \mathrm{O}$ without ultrasonic irradiation. Figure 7 d,e indicates the original morphology of S6 sample. The mixture of microrods, microsheets and microparticles of 1 were obtained with $0.1 \mathrm{M}$ concentration of initial reagents in $\mathrm{H}_{2} \mathrm{O}$ under ultrasonic irradiation. Figure 8a-c indicates the original morphology of S7 sample. The microstructure of $\mathbf{1}$ composed from nanoparticles and spongy nanopores composed from nanoparticles of $\mathbf{1}$ were formed in 7:3 mixture of $\mathrm{MeCN}: \mathrm{H}_{2} \mathrm{O}$ with $0.1 \mathrm{M}$ concentration of initial reagents without ultrasonic irradiation. Figure 8d,e indicates the original morphology of S8 sample. Microstructure composed from microrods, particles, sheets and cubes of 1 were formed in 7:3 mixture of $\mathrm{MeCN}: \mathrm{H}_{2} \mathrm{O}$ with $0.1 \mathrm{M}$ concentration of initial reagents under ultrasonic irradiation. Table 3 summarizes the above mentioned results about these eight samples. By considering these SEM images, we can reach the following attractive results:

i. $\quad$ A comparison between the SEM images of S1-S4 (Figures 5-6, respectively) and S5S8 (Figures 7-8, respectively) samples indicated that with the lower concentration of initial reagents, the synthesis process may be more successful than with higher concentration of initial reagents for preparation of nanostructures with regular and monosized morphology. 
ii. A comparison between the SEM images of compound $\mathbf{1}$ samples which were synthesized in the presence of MeCN (S3, S4, Figure 6 and S7, S8, Figure 8) showed that the possibility of achieving to the spongy nanoporous structure of $\mathbf{1}$ is higher in $\mathrm{MeCN}$ in comparison to $\mathrm{H}_{2} \mathrm{O}$.

iii. A comparison between the SEM images of S1 and S2 (Figure 5) samples indicated that in the presence of ultrasonic waves, the tendency for agglomeration of components of 1 was increased.

iv. A comparison between the SEM images of S3 and S4 (Figure 6) samples indicated that how the ultrasonic waves can affect on the morphology of a chemical compound.

v. Sonochemical synthesis is usually an effective procedure for preparation of nanostructure materials, but a comparison between the SEM images of S5 and S6 (Figure 7) samples indicated that in some cases, it may provide appropriate energy for agglomeration of the particles.

vi. A comparison between the SEM images of S7 and S8 (Figure 8) samples indicated that in the presence of ultrasonic waves, the possibility of formation compound $\mathbf{1}$ nanoparticle is lower than without it.

vii. If we want to synthesis compound $\mathbf{1}$ with nanoporous microcube morphology, we should use $0.025 \mathrm{M}$ concentration of initial reagents in the mixture of $\mathrm{MeCN}: \mathrm{H}_{2} \mathrm{O}$ under ultrasonic irradiation and if we want to synthesis compound $\mathbf{1}$ with nanoporous microrod morphology, we should use $0.1 \mathrm{M}$ concentration of initial reagents in $\mathrm{H}_{2} \mathrm{O}$ without ultrasonic irradiation.

TG-DTA data (Figure S2a in the SI) indicated that S1 sample of $\mathbf{1}$ is stable up to $280{ }^{\circ} \mathrm{C}$. The exothermic mass loss of $31.7 \%$ between $280-520{ }^{\circ} \mathrm{C}$ may be attributed to removal $\mathrm{Cl}_{2}$ and $\mathrm{CO}_{2}$ gas molecules and partial destruction of 3-HClb,3-Clb in 1 (Calcd. 30.8\%). Other samples (S2S8) showed similar thermal behavior to S1 (Figure S2b-h in the SI). But S4 (Figure S2d in the SI), S5 (Figure S2e in the SI) and S7 (Figure S2g in the SI) samples, have further endothermic 
mass losses of $4.8 \%$ between $140-200{ }^{\circ} \mathrm{C}, 4.7 \%$ between $142-197{ }^{\circ} \mathrm{C}$ and $2.0 \%$ between $142-180$ ${ }^{\circ} \mathrm{C}$, respectively. SEM images showed that these three samples have the nanoporous structure (Figures 6c-e, 7a-c and 8a-c), thus these mass losses between $140-200{ }^{\circ} \mathrm{C}$ may be attributed to trapping some species such as solvents or unreacted initial materials in the structure of them. The PXRD pattern of these samples also have an extra peak at $2 \theta=7.0^{\circ}$ (Figure $4 \mathrm{e}, \mathrm{f}, \mathrm{h}$ ) which did not observe in other patterns and it may be attributed to crystalized trapping species in the nanoporous structure of $\mathbf{1}$ in S4, S5 and S7 samples.

\section{Conclusion}

In summary, a new two-dimensional thallium-based supramolecular polymer $\left[\mathrm{Tl}\left(\mu_{3}-3-\mathrm{HClb}\right)\left(\mu_{3^{-}}\right.\right.$ 3-Clb) $]_{n}(\mathbf{1})$ with linear thallophilic and covalent hydrogen bonding interactions has been synthesized and structurally characterized by single crystal X-ray crystallography. 3-HClb did not deprotonate completely in $\mathbf{1}$ and involving in covalent hydrogen bonding interaction with 3 $\mathrm{Clb}^{-}$. The $\mathrm{Tl}$ ion in $\mathbf{1}$ has $\mathbf{T l O}_{6} \mathrm{Tl}_{2}$ holodirected coordination sphere. $\mathrm{Tl} \cdots \mathrm{Tl}$ distance in $\mathbf{1}$ is comparable with those reported previously. A weak broadband around $3250-3650 \mathrm{~cm}^{-1}$ was observed which indicated the existence of strong hydrogen bonding interaction in $\mathbf{1}$. In order to evaluate the effects of concentration, ultrasonic irradiation and types of the solvent on morphology and thermal behavior of $\mathbf{1}$, eight samples of it were synthesized under different conditions. With a lower concentration of initial reagents, the synthesis process may be more successful than with higher concentration of initial reagents for preparation of nanostructures with regular and monosized morphology. The possibility of achieving to the spongy nanoporous structure of $\mathbf{1}$ is higher in MeCN in comparison to $\mathrm{H}_{2} \mathrm{O}$. In the presence of ultrasonic waves, the tendency for agglomeration of components of $\mathbf{1}$ was increased. Sonochemical synthesis is not usually an effective procedure for the preparation of nanostructure materials and in some cases; it may provide appropriate energy for agglomeration of the particles. Nanoporous microcube of $\mathbf{1}$, can be synthesized with $0.025 \mathrm{M}$ concentration of initial reagents in a mixture of $\mathrm{MeCN}: \mathrm{H}_{2} \mathrm{O}$ 
under ultrasonic irradiation and nanoporous microrod of $\mathbf{1}$, can be synthesized with $0.1 \mathrm{M}$ concentration of initial reagents in $\mathrm{H}_{2} \mathrm{O}$ without ultrasonic irradiation. The porous structure of $\mathbf{1}$ has endothermic mass losses of about $5.0 \%$ between $140-200{ }^{\circ} \mathrm{C}$ in TG-DTA curve which may be attributed to trapping some species such as solvents or unreacted initial materials in the structure of them. The PXRD patterns of these samples also have an extra peak at $2 \theta=7.0^{\circ}$ which did not observe in other patterns and it may be attributed to crystalized trapping species in the nanoporous structure of $\mathbf{1}$.

\section{Supplementary material.}

Complete bond lengths and angles, co-ordinates and displacement parameters have been deposited at Cambridge Crystallography Data Center. Supplementary data are available from the CCDC, 12 Union Road, Cambridge CB2 1EZ, UK on request, quoting the deposition number 1863963 for compound 1. Electronic Supplementary Information (ESI) including other figures and TG-DTA curves are available.

\section{Acknowledgements}

The authors would like to acknowledge the financial support of University of Tehran for this research under grant number 01/1/389845.

\section{References}

[1] H. Günay, A. Tolga Çolak, E. Temel, Ö. Saniye Bayraktar, F. Çolak, O. Büyükgüngör, J. Coord. Chem. 2016, 9, 1499-1513.

[2] E. Mirzadeh, K. Akhbari, CrystEngComm. 2016, 18, 7410-7424.

[3] Y. Noori, K. Akhbari, RSC Adv. 2017, 7, 1782-1808.

[4] M. O’Keeffe, O.M. Yaghi, Chem. Rev. 2012, 112, 675-702. 
[5] F. Shahangi Shirazi, K. Akhbari, Inorg. Chem. Acta. 2015, 436, 1-6.

[6] S. Janiak, J.K. Vieth, New J. Chem. 2010, 34, 2366-2388.

[7] F. Shahangi Shirazi, K. Akhbari, J. Iran. Chem. Soc. 2017, 14, 1519-1525.

[8] Y.-Q. Hu, M.-H. Zeng, K. Zhang, S. Hu, F.-F. Zhou, M. Kurmoo, J. Am. Chem. Soc. 2013, 135, 7901-7908.

[9] K. Akhbari, A. Morsali, CrystEngComm. 2012, 14, 1618-1628.

[10] K. Akhbari, A. Morsali, J. Organomet. Chem. 2007, 692, 5109-5112.

[11] K. Akhbari, A. Morsali, J. Organomet. Chem. 2007, 692 5141-5146.

[12] S. Hunig, H. Meixner, T. Metzenthin, U. Langohr, J.U. Schutz, H.-C. Wolf, E. Tillmanns, Adv. Mater. 1990, 2, 361-365.

[13] K. Akhbari, A. Morsali, Coord. Chem. Rev. 2010, 254, 1977-2006.

[14] R. A. Agarwal. Inorg. Chem. Commun. 2016, 70, 115-117.

[15] Q. Y. Wang, Y. He, Q. H. Meng, X. L. Zhang, Z. T. Zhang J. Coord. Chem, 2017, 70, 11051120.

[16] L. M. Epstein, E. S. Shubina. Coord. Chem. Rev. 2002, 231, 165-181.

[17] A. M, Beatty, Coord. Chem, Rev, 2003, 246, 131-143.

[18] S. Wang, P. Liebing, F. Oehler, J. W. Gilje, C. G. Hrib, F. T. Edelmann, Cryst. Growth Des. 2017, 17, 3402-3410.

[19] A. M. Spokoyny, D. Kim, A. Sumreina, Ch. A. Mirkin, Chem. Soc. Rev. 2009, 38, $1217-$ 1227.

[20] K. Akhbari, A. Morsali, Inorg. Chem. 2013, 52, 2787-2789.

[21] E. Mirzadeh, K. Akhbari, A. Phuruangrat, F. Costantino, Ultrason. Sonochem. 2017, 35, 382-388.

[22] Y. Noori, K. Akhbari, A. Phuruangrat, F. Costantino, Ultrason. Sonochem. 2017, 35, 36-44.

[23] Y. Noori, K. Akhbari, A. Phuruangrat, F. Costantino, Ultrason. Sonochem. 2018, 40, 17-20.

[24] K. Akhbari, S. Karami, Z. Saedi, Ultrason. Sonochem. 2018, 42, 640-646.

[25] M. Salavati-Niasari, J. Mol. Catal. A: Chem., 2008, 283, 120-128

This article is protected by copyright. All rights reserved. 
[26] M. Salavati-Niasari, M. Dadkhah, F. Davar, Inorg. Chim. Acta., 2009, 362, 3969-3974

[27] M. Salavati-Niasari, J. Mol. Catal. A: Chem., 2005, 229, 159-164

[28] A. Zolfaghari, F. Ataherian, M. Ghaemi, A. Gholami, Electrochim. Acta., 2007, 52, 28062814

[29] K.S. Suslick, S.B. Choe, A.A. Cichowlas, M.W. Grinstaff, Nature, 1991, 353, 414-416.

[30] K. Okitsu, Y. Mizukoshi, H. Bandow, Y. Maeda, T. Yamamoto, Y. Nagata, Ultrason. Sonochem. 1996, 3, S249-S251.

[31] T.J. Mason, Sonochemistry, Oxford University Press Inc., New York, 1999

[32] A. Gedanken, Ultrason. Sonochem. 2004, 11, 47-55.

[33] F. Shahangi Shirazi, K. Akhbari, Ultrason. Sonochem. 2016, 31, 51-61.

[34] E. Mirzadeh, K. Akhbari, J. White, Appl Organometal Chem. 2018, e4313, 1-8.

[35] M. Puszynska-Tuszkanow, Z. Staszak, T. Misiaszek, M. T.Klepka, A. Wolska, A. Drzewiecka-Antonik, H. Faltynowi,cz, M. Cieslak-Golonka, Chem. Phys. Lett, 2014, 597, 94-98. [36] C. F. Macrae, P. R. Edgington, P. McCabe, E. Pidcock, G. P. Shields, R. Taylor, M. Towler \& J. van de Streek, J. Appl. Cryst. 2006, 39, 453-457.

[37] G. M. Sheldrick, Acta Cryst. Sect. C. 2015, 71, 3-8.

[38] L. J. Farrugia, J. Appl. Cryst. 1997, 30, 565-565.

[39] L. J. Farrugia, J. Appl. Cryst. 1999, 32, 837-838.

[40] A. Bondi, J. phys. Chem. 1964, 68, 441-451.

[41] K. H. Stone, D. L. Turner, M. P. Singh, T. P. Vaid, P. W. Stephens, Acta. Cryst., 2011, B67, 409-415.

[42] V. Kumar, V. Singh, Ajit N. Gupta, M. G. B. Drew, N. Singh, Dalton Trans., 2015,44, 17161723.

[43] O. Kristiansson, Eur. J. Inorg. Chem. 2002, 2355-2361

[44] K. Akhbari, A. Morsali, Polyhedron, 2011, 30, 2459-2465.

This article is protected by copyright. All rights reserved. 
[45] J. Cullinane, A. Jolleys, F. Mair, Dalton Trans, 2013, 42, 11971-11975.

[46] N. Alexander, K. Ramalingam, C. Rizzoli, Inorg. Chim. Acta., 2011, 365, 480-483

[47] Montana V. Childress, D. Millar, Todd M. Alam, Kevin A. Kreisel, Glenn P. A. Yap, Lev

N. Zakharov, James A. Golen, Arnold L. Rheingold, and Linda H. Doerrer, Inorg. Chem., 2006, 45, 3864-3877.

[48] K. Akhbari, A. Morsali, Polyhedron. 2011, 30, 1456-1462.

[49] K. Akhbari, A. Morsali, Inorg. Chim. Acta. 2009, 362, 1692-1700.

[50] K. Akhbari, A. Morsali, J. Mol. Struct. 2008, 878, 65-70.

[51] K. Akhbari, A. Morsali, Inorg. Chem. Commun. 2007, 10, 1189-1193.

[52] K. Akhbari, A. Morsali, Inorg. Chem. Commun. 2007, 10, 178-182.

[53] M. Moeinian, K. Akhbari, J. Boonmak, S. Youngme, Polyhedron. 2016, 118, 6-11.

[54] M. Moeinian, K. Akhbari, S. Kawata, R. Ishikawa, RSC Adv. 2016, 6, 82447-82449.

Table 1. Crystal data and structure refinement for compound $\left[\mathrm{Tl}\left(\mu_{3}-3-\mathrm{HClb}\right)\left(\mu_{3}-3-\mathrm{Clb}\right)\right]_{\mathrm{n}}(\mathbf{1})$.

\begin{tabular}{ll}
\hline Identification code & $\mathbf{1}$ \\
Empirical formula & $\mathrm{C}_{14} \mathrm{H}_{9} \mathrm{Cl}_{2} \mathrm{O}_{4} \mathrm{Tl}$ \\
Formula weight & 516.48 \\
Temperature & $100.0(2) \mathrm{K}$ \\
Wavelength & $0.71073 \AA$ \\
Crystal system & monoclinic \\
Space group & $\mathrm{C} 2 / \mathrm{c}$ \\
Unit cell dimensions & $\mathrm{a}=32.223(6) \AA$ \\
& $\mathrm{b}=3.7780(8) \AA$ \\
& $\mathrm{c}=11.603(2) \AA$ \\
\hline
\end{tabular}

This article is protected by copyright. All rights reserved. 


\begin{tabular}{ll}
\hline & $\alpha=90.00^{\circ}$ \\
& $\beta=96.52(3)^{\circ}$ \\
& $\gamma=90.00^{\circ}$ \\
Volume & $1403.4(5) \AA^{3}$ \\
$Z$ & 4 \\
Density (calculated) & $2.444{\mathrm{~g} . \mathrm{cm}^{-3}}^{-1}$ \\
Absorption coefficient & $11.900 \mathrm{~mm}^{-1}$ \\
$F(000)$ & 960 \\
Crystal size & $0.04 \times 0.05 \times 0.03 \mathrm{~mm}^{3}$ \\
Theta range for data collection & 4.9 to $31.9^{\circ}$ \\
Index ranges & $-42 \leq \mathrm{h} \leq 42$ \\
& $-5 \leq \mathrm{k} \leq 5$ \\
& $-16 \leq 1 \leq 16$ \\
Independent reflections & 1900 \\
Absorption correction & $\mathrm{multi}^{-\mathrm{scan}}$ \\
& $1906 / 0 / 97$ \\
Data / restraints / parameters & 1.097 \\
Goodness-of-fit on $\mathrm{F}^{2}$ & $\mathrm{R}_{1}=0.0222$ \\
Final $R$ indices [I $2 \sigma(I)]$ & $\mathrm{wR}=0.0580$ \\
$R$ Indices (all data) & $\mathrm{R}_{1}=0.0223$ \\
& $\mathrm{wR}=0.0581$ \\
Largest diff. Peak, hole & 0.935 and $-1.622 \mathrm{e} . \AA^{-3}$ \\
\hline
\end{tabular}

Table 2. Hydrogen bond for compound $\left[\mathrm{Tl}\left(\mu_{3}-3-\mathrm{HClb}\right)\left(\mu_{3}-3-\mathrm{Clb}\right)\right]_{\mathrm{n}}(\mathbf{1}),\left[/ \AA\right.$ and $\left./{ }^{\circ}\right]$.

\begin{tabular}{lllll}
\hline $\mathrm{D}-\mathrm{H} \ldots \mathrm{A}$ & $\mathrm{d}(\mathrm{D}-\mathrm{H})$ & $\mathrm{d}(\mathrm{H} \ldots \mathrm{A})$ & $\mathrm{d}(\mathrm{D} \ldots \mathrm{A})$ & $<(\mathrm{DHA})$ \\
\hline
\end{tabular}

This article is protected by copyright. All rights reserved. 


\begin{tabular}{lllll}
\hline $\mathrm{C}(1)-\mathrm{H}(1) \ldots \mathrm{O}(2)$ & $1.229(2)$ & $2.427(2)$ & $3.128(3)$ & $113.53(11)$
\end{tabular}

Table 3. A summary of reaction conditions for synthesis eight samples of $\left[\mathrm{Tl}\left(\mu_{3}-3-\mathrm{HClb}\right)\left(\mu_{3}-3-\right.\right.$ $\mathrm{Clb})]_{\mathrm{n}}(\mathbf{1})$.

\begin{tabular}{|c|c|c|c|c|}
\hline $\begin{array}{c}\text { Sample } \\
\text { code }\end{array}$ & $\begin{array}{c}\text { Concentration of } \\
\text { 3-HClb,KOH,TINO }\end{array}$ & Solvent & $\begin{array}{l}\text { Ultrasonic } \\
\text { irradiation }\end{array}$ & Morphology of 1 \\
\hline S1 & $0.025 \mathrm{M}$ & $\mathrm{H}_{2} \mathrm{O}$ & No & $\begin{array}{l}\text { Nanoflower composed } \\
\text { from nanorods and } \\
\text { nanosheets }\end{array}$ \\
\hline S2 & $0.025 \mathrm{M}$ & $\mathrm{H}_{2} \mathrm{O}$ & Yes & $\begin{array}{l}\text { Agglomerated } \\
\text { nanosheets }\end{array}$ \\
\hline S3 & $0.025 \mathrm{M}$ & $\begin{array}{c}\mathrm{MeCN}: \mathrm{H}_{2} \mathrm{O} \\
(7: 3)\end{array}$ & No & $\begin{array}{l}\text { Spongy microstructure } \\
\text { composed from nanorods } \\
\text { and nanosheets }\end{array}$ \\
\hline S4 & $0.025 \mathrm{M}$ & $\begin{array}{c}\mathrm{MeCN}: \mathrm{H}_{2} \mathrm{O} \\
(7: 3)\end{array}$ & Yes & $\begin{array}{l}\text { Nanoporous microcubes } \\
\text { composed from } \\
\text { nanoparticles }\end{array}$ \\
\hline S5 & $0.1 \mathrm{M}$ & $\mathrm{H}_{2} \mathrm{O}$ & No & nanoporous microrods \\
\hline S6 & $0.1 \mathrm{M}$ & $\mathrm{H}_{2} \mathrm{O}$ & Yes & $\begin{array}{l}\text { Microrods, microsheets } \\
\text { and microparticles }\end{array}$ \\
\hline S7 & $0.1 \mathrm{M}$ & $\begin{array}{c}\mathrm{MeCN}: \mathrm{H}_{2} \mathrm{O} \\
(7: 3)\end{array}$ & No & $\begin{array}{l}\text { Microstructure composed } \\
\text { from nanoparticles and } \\
\text { spongy nanopores } \\
\text { composed from } \\
\text { nanoparticles }\end{array}$ \\
\hline S8 & $0.1 \mathrm{M}$ & $\mathrm{MeCN}: \mathrm{H}_{2} \mathrm{O}$ & Yes & $\begin{array}{l}\text { Microstructure composed } \\
\text { from microrods, } \\
\text { particles, sheets and }\end{array}$ \\
\hline
\end{tabular}

This article is protected by copyright. All rights reserved. 


\begin{tabular}{|l|l|l|l|l|}
\hline & & $(7: 3)$ & & cubes \\
\hline
\end{tabular}

\section{Figure Captions:}

Figure 1. a) Covalent hydrogen bonding between $3-\mathrm{HClb}$ and $3-\mathrm{Clb}^{-}$along the crystallographic $b$ axis and b) thallium(I) coordination sphere in $\left[\mathrm{Tl}\left(\mu_{3}-3-\mathrm{HClb}\right)\left(\mu_{3}-3-\mathrm{Clb}\right)\right]_{\mathrm{n}}(\mathbf{1}),(\mathrm{Tl}=$ purple, $\mathrm{O}=$ red, $\mathrm{C}=$ gray, $\mathrm{Cl}=$ green and $\mathrm{H}=$ white, $\mathrm{Tl}-\mathrm{O}$ bonds were shown with dashed blue lines. In part b, $\mathrm{H}$ atoms have been omitted for clarity).

Figure 2. a) A fragment of $2 \mathrm{D}$ supramolecular polymer in $\left[\mathrm{Tl}\left(\mu_{3}-3-\mathrm{HClb}\right)\left(\mu_{3}-3-\mathrm{Clb}\right)\right]_{\mathrm{n}}(\mathbf{1})$ along the crystallographic $a$ axis showing the coordination behavior of the $3-\mathrm{HClb}$ and $3-\mathrm{Clb}^{-}, \mathrm{b}$ ) lozenge framework along the crystallographic $c$ axis and c) linear thallophilic interactions in $\mathbf{1}$ along the crystallographic $a$ axis, $(\mathrm{Tl}=$ purple, $\mathrm{O}=$ red, $\mathrm{C}=$ gray, $\mathrm{Cl}=$ green and $\mathrm{H}=$ white, $\mathrm{Tl}$ $\mathrm{O}$ and $\mathrm{Tl}-\mathrm{Tl}$ bonds were shown with dashed blue lines. In part c, $\mathrm{H}$ atoms have been omitted for clarity).

Figure 3. IR spectra of a) $\left[\mathrm{Tl}\left(\mu_{3}-3-\mathrm{HClb}\right)\left(\mu_{3}-3-\mathrm{Clb}\right)\right]_{\mathrm{n}}(1)$ single crystal, b) S1, c) S2, d) S3, e) S4, f) $\mathrm{S} 5$, g) S6, h) S7 and i) S8 sample.

Figure 4. XRD patterns; a) simulated pattern based on single crystal data of $\left[\mathrm{Tl}\left(\mu_{3}-3-\mathrm{HClb}\right)\left(\mu_{3^{-}}\right.\right.$ 3-Clb)] $]_{\mathrm{n}}(1)$, b) S1, c) S2, d) S3, e) S4, f) S5, g) S6, h) S7 and i) S8 sample.

Figure 5. SEM images of $S 1(a, b)$ and $S 2(c, d)$ samples.

Figure 6. SEM images of S3 (a,b) and S4 (c-e)samples.

Figure 7. SEM images of S5 (a-c) and S6 (d,e) samples.

Figure 8. SEM images of S7 (a-c) and S8 (d,e) samples. 


\section{a}

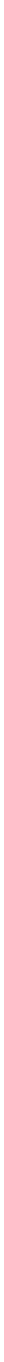

$$
\text { AOC_4747_f1a.tif }
$$

This article is protected by copyright. All rights reserved. 


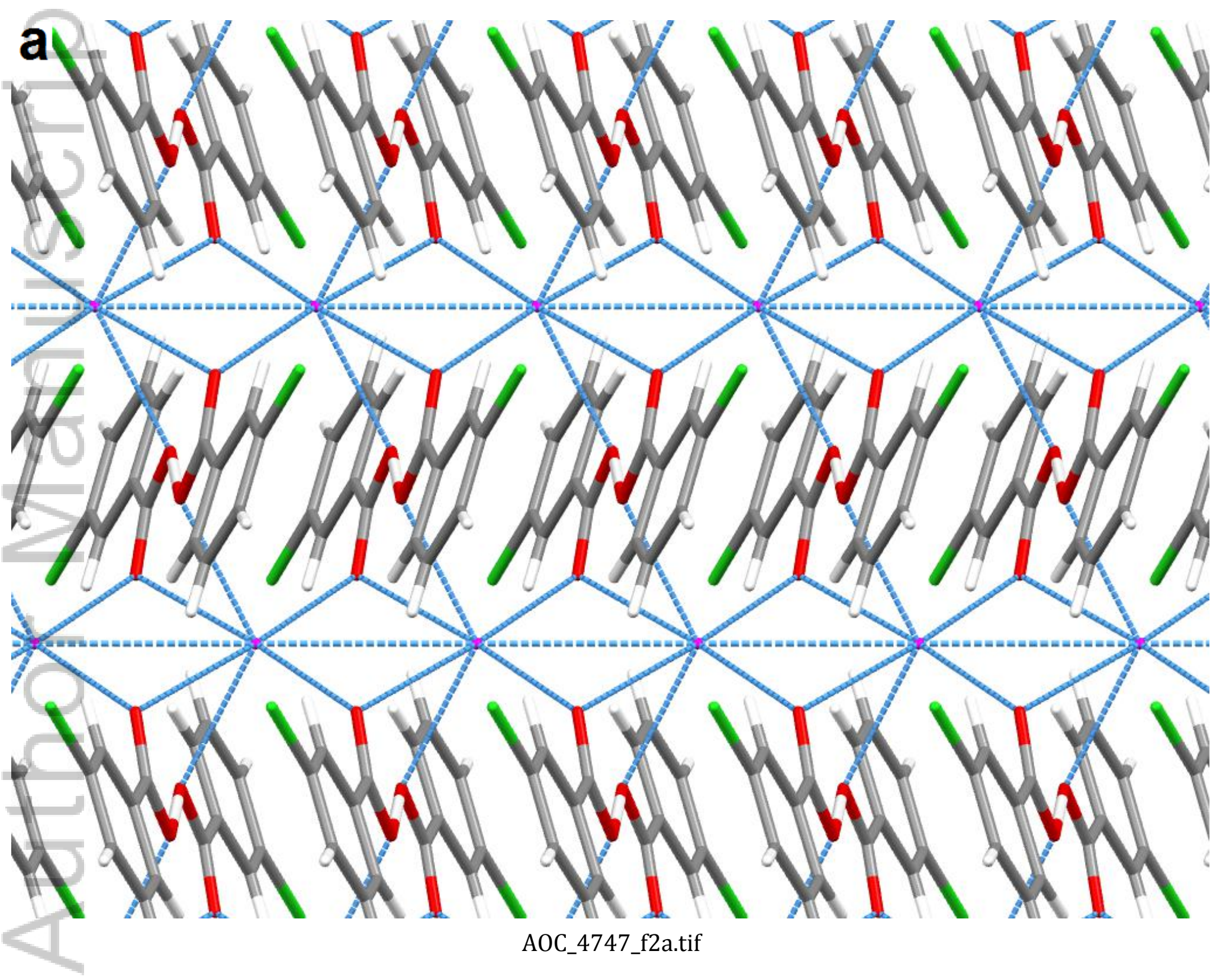

This article is protected by copyright. All rights reserved. 


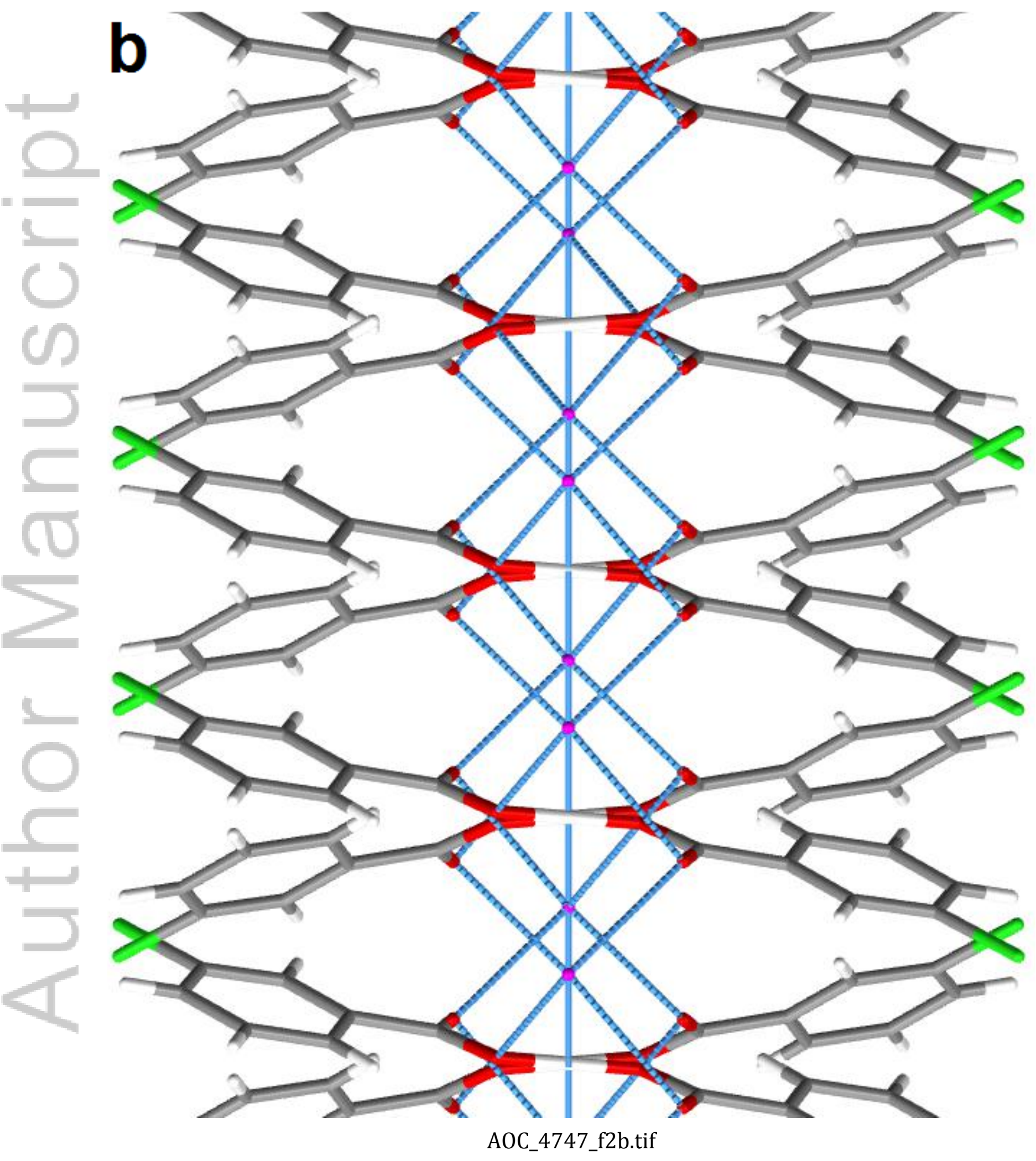

This article is protected by copyright. All rights reserved. 


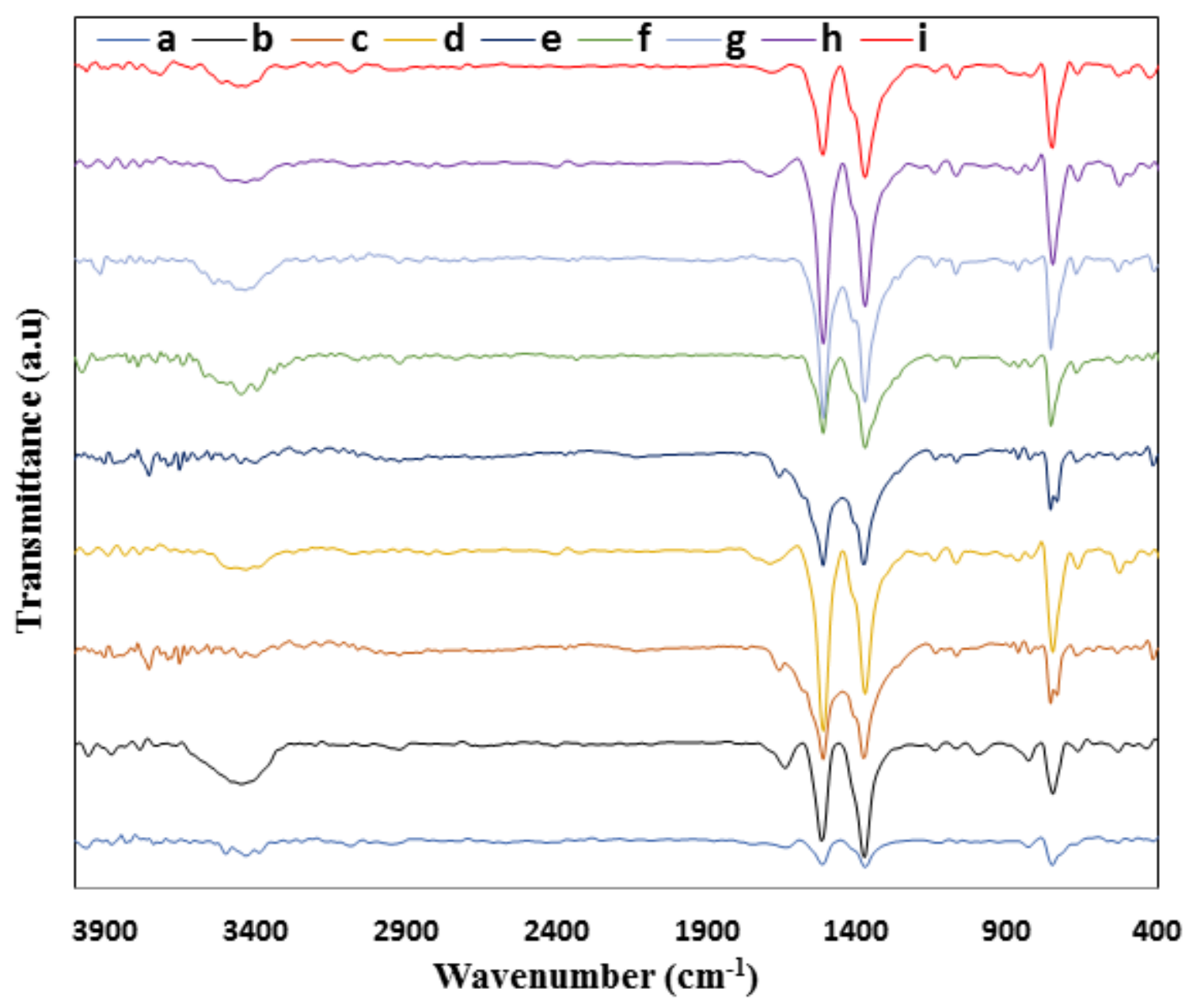

AOC_4747_f3.tif

This article is protected by copyright. All rights reserved. 


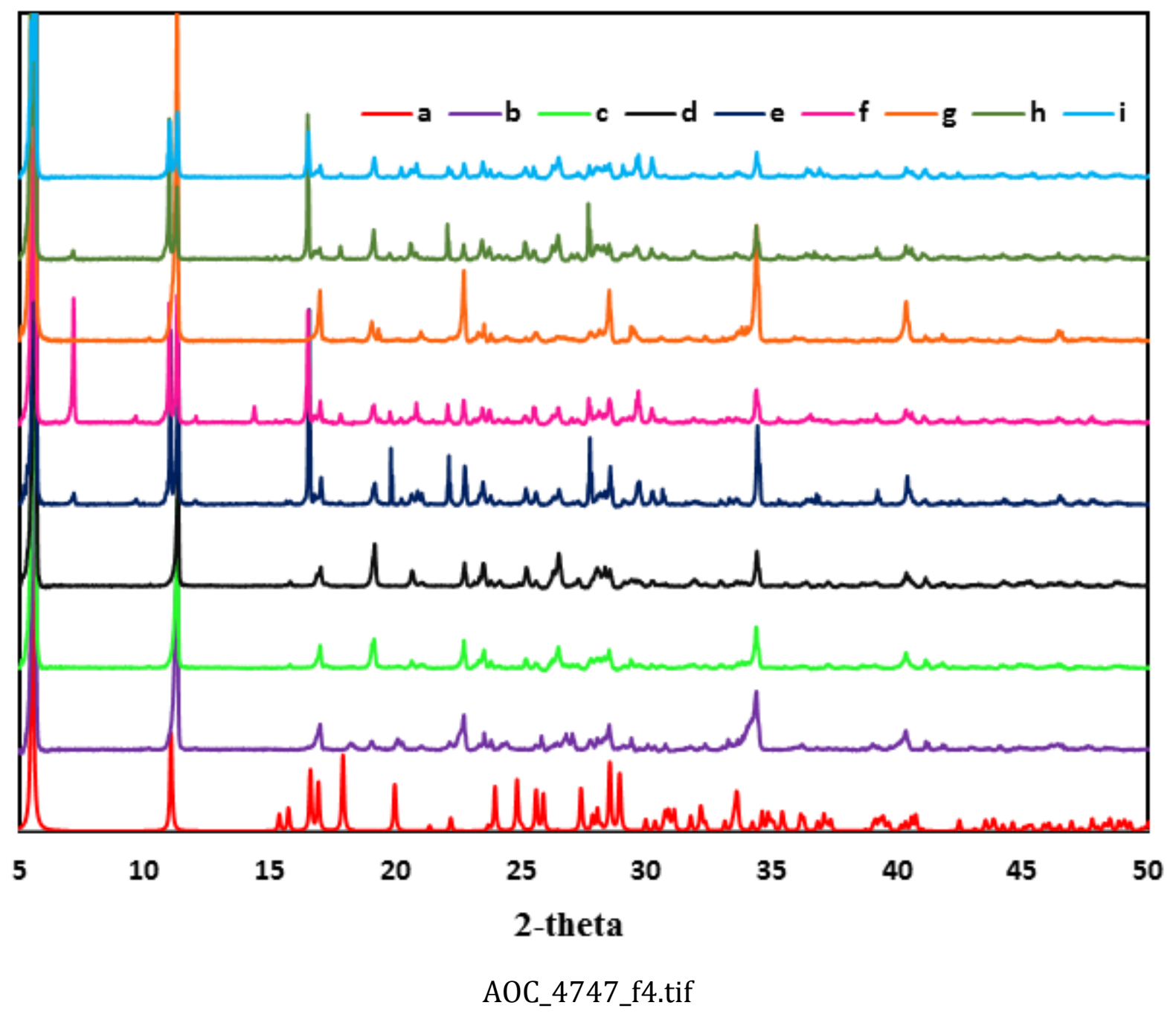

This article is protected by copyright. All rights reserved. 


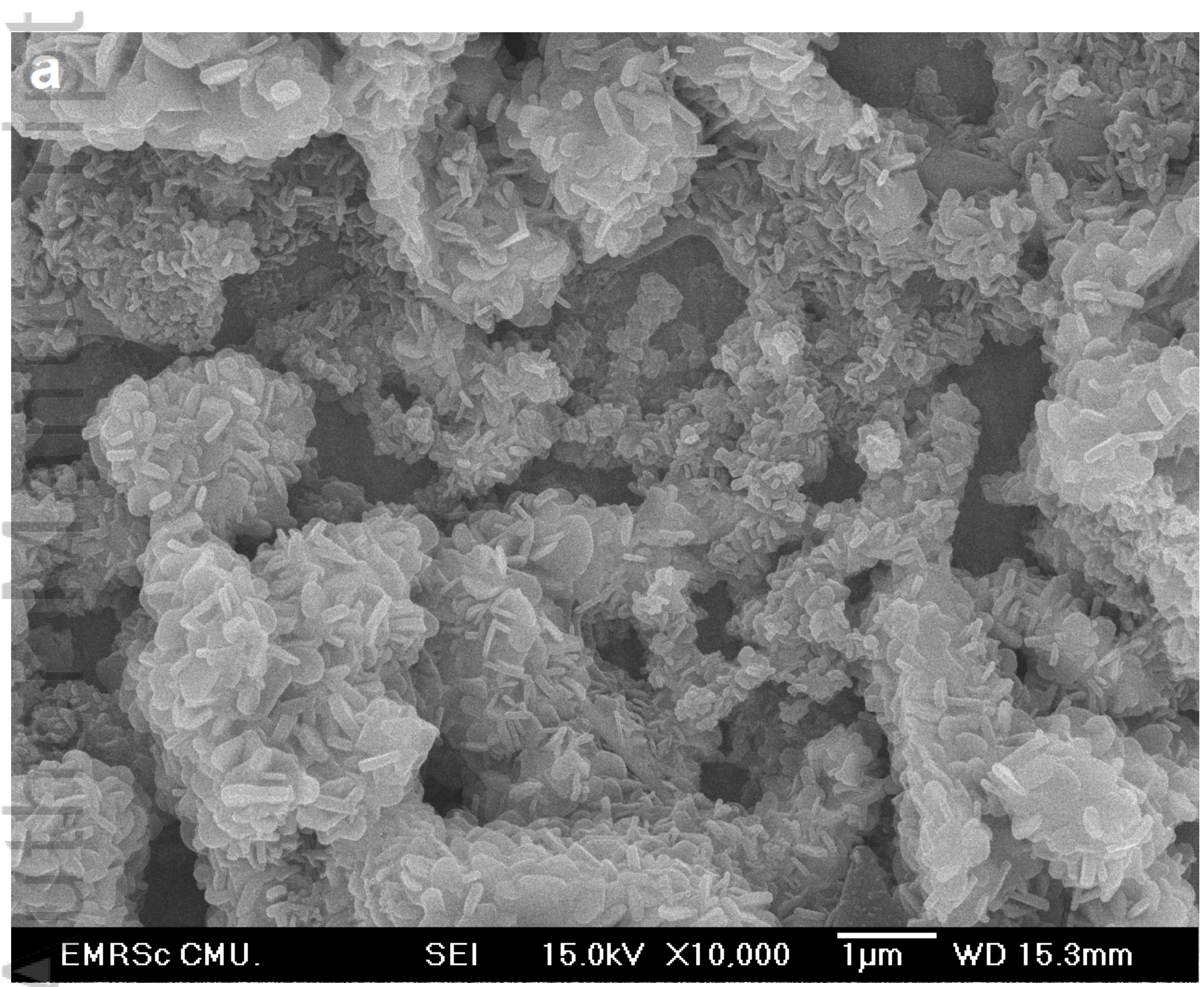

A0C_4747_f5a.tif

This article is protected by copyright. All rights reserved. 


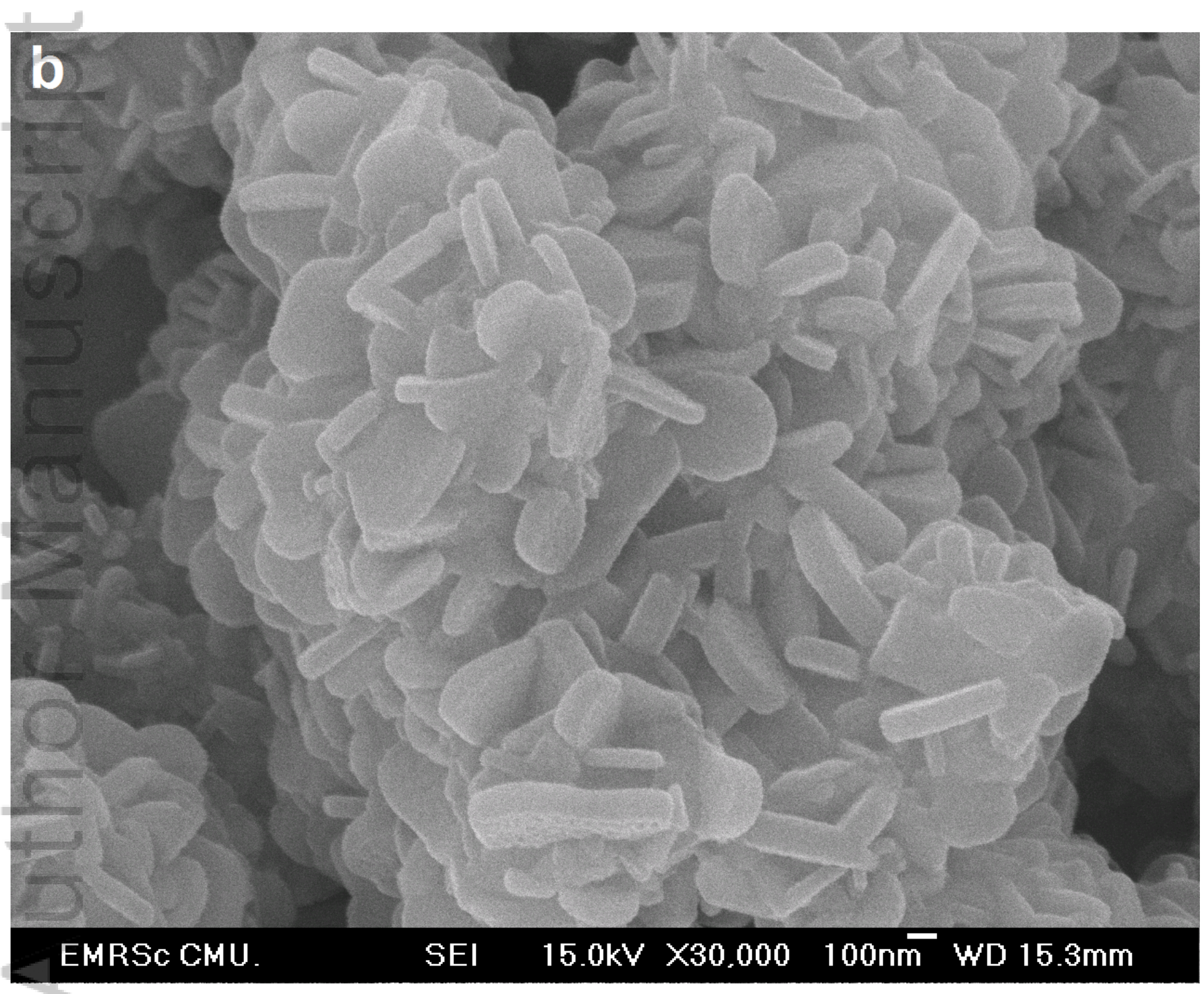

A0C_4747_f5b.tif

This article is protected by copyright. All rights reserved. 


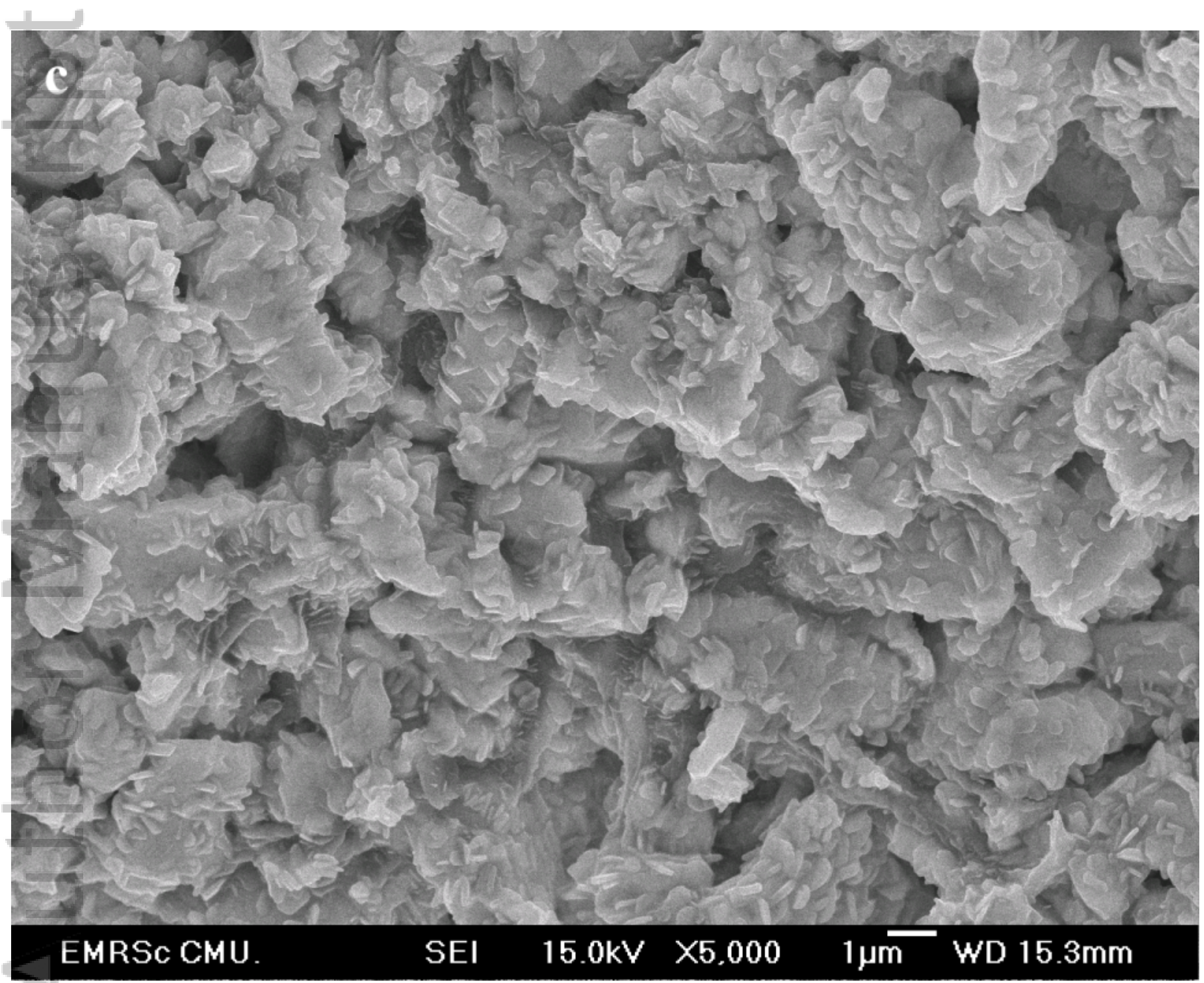

AOC_4747_f5c.tif

This article is protected by copyright. All rights reserved. 


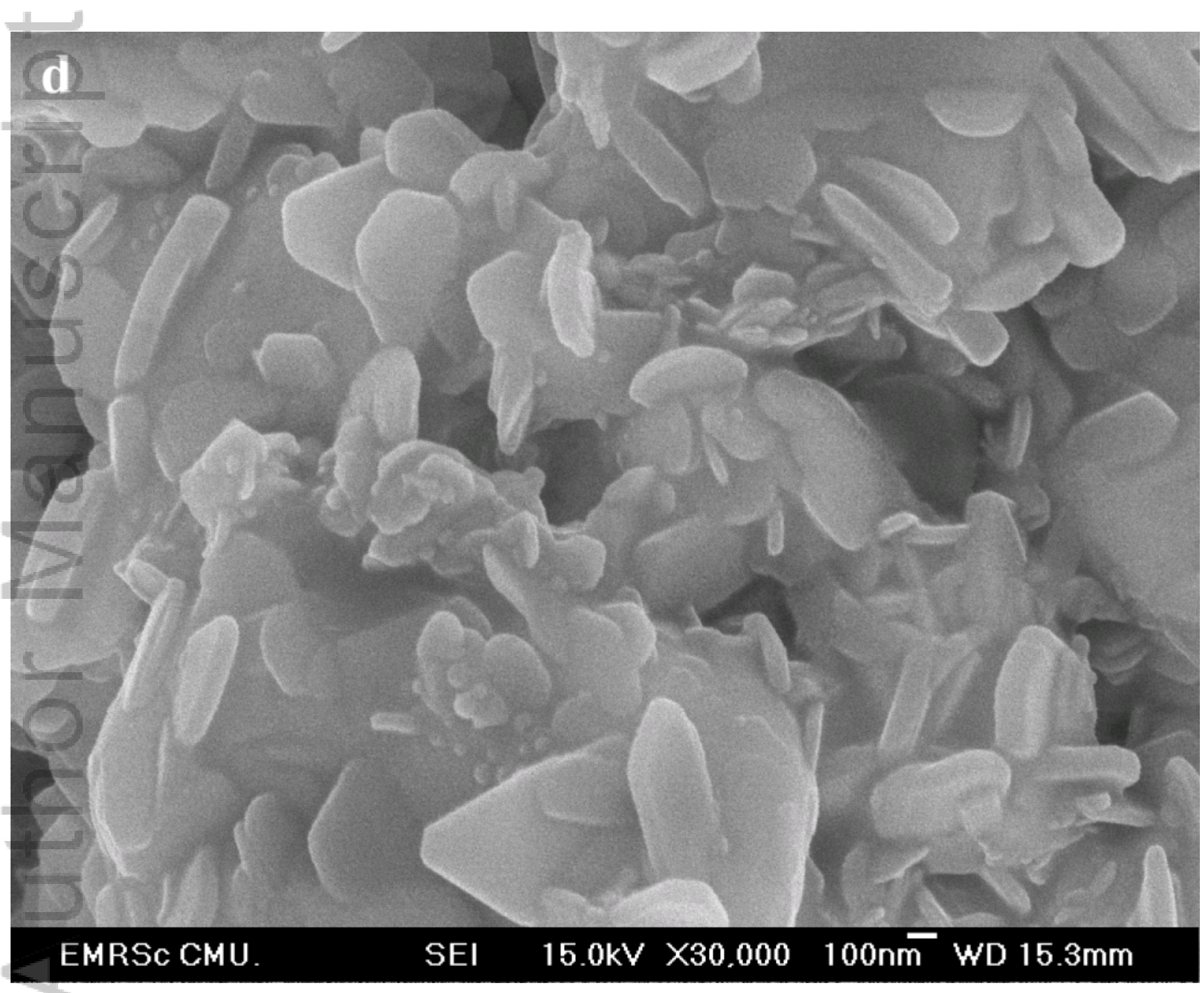

A0C_4747_f5d.tif

This article is protected by copyright. All rights reserved. 


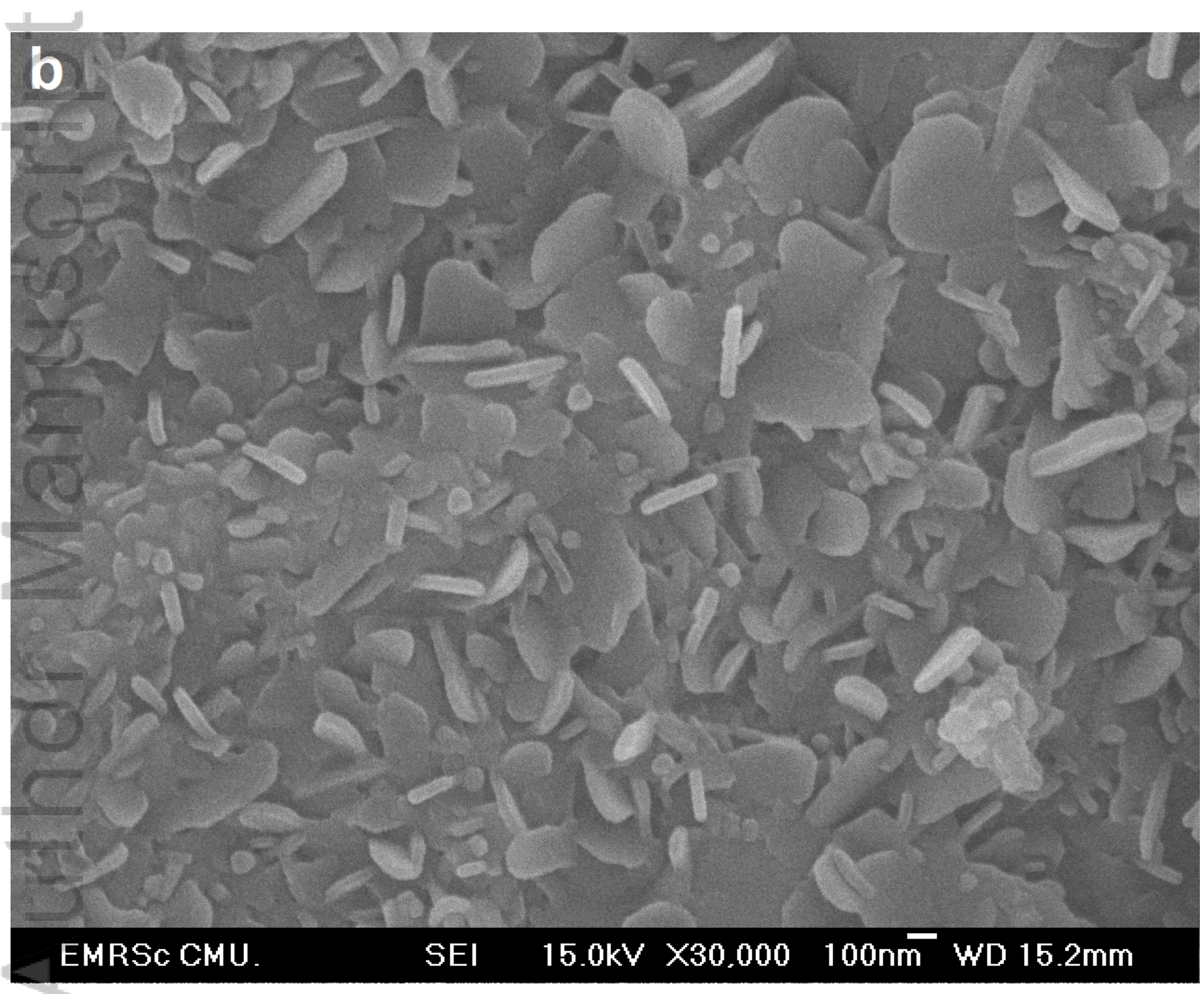

A0C_4747_f6b.tif

This article is protected by copyright. All rights reserved. 


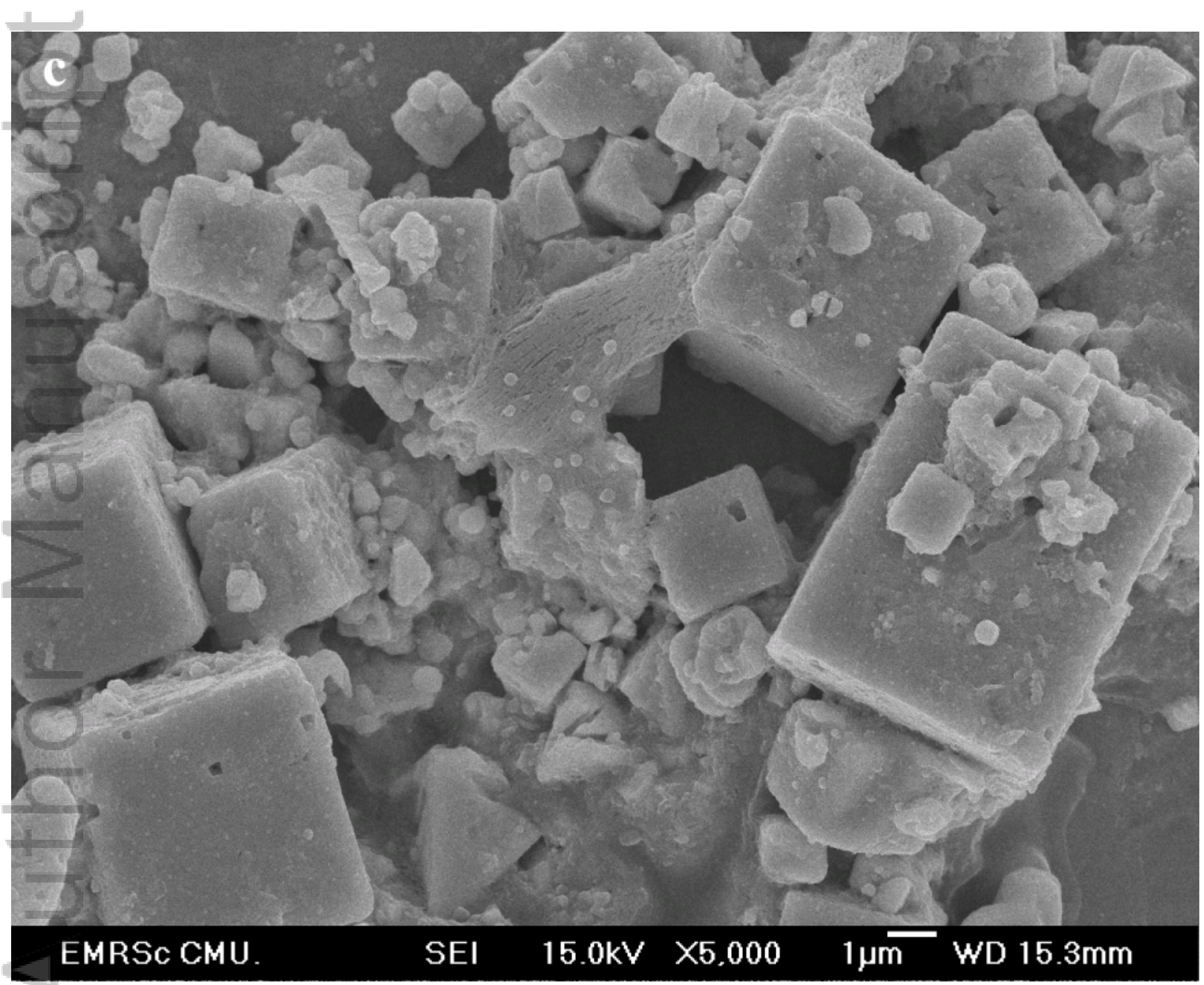

A0C_4747_f6c.tif

This article is protected by copyright. All rights reserved. 


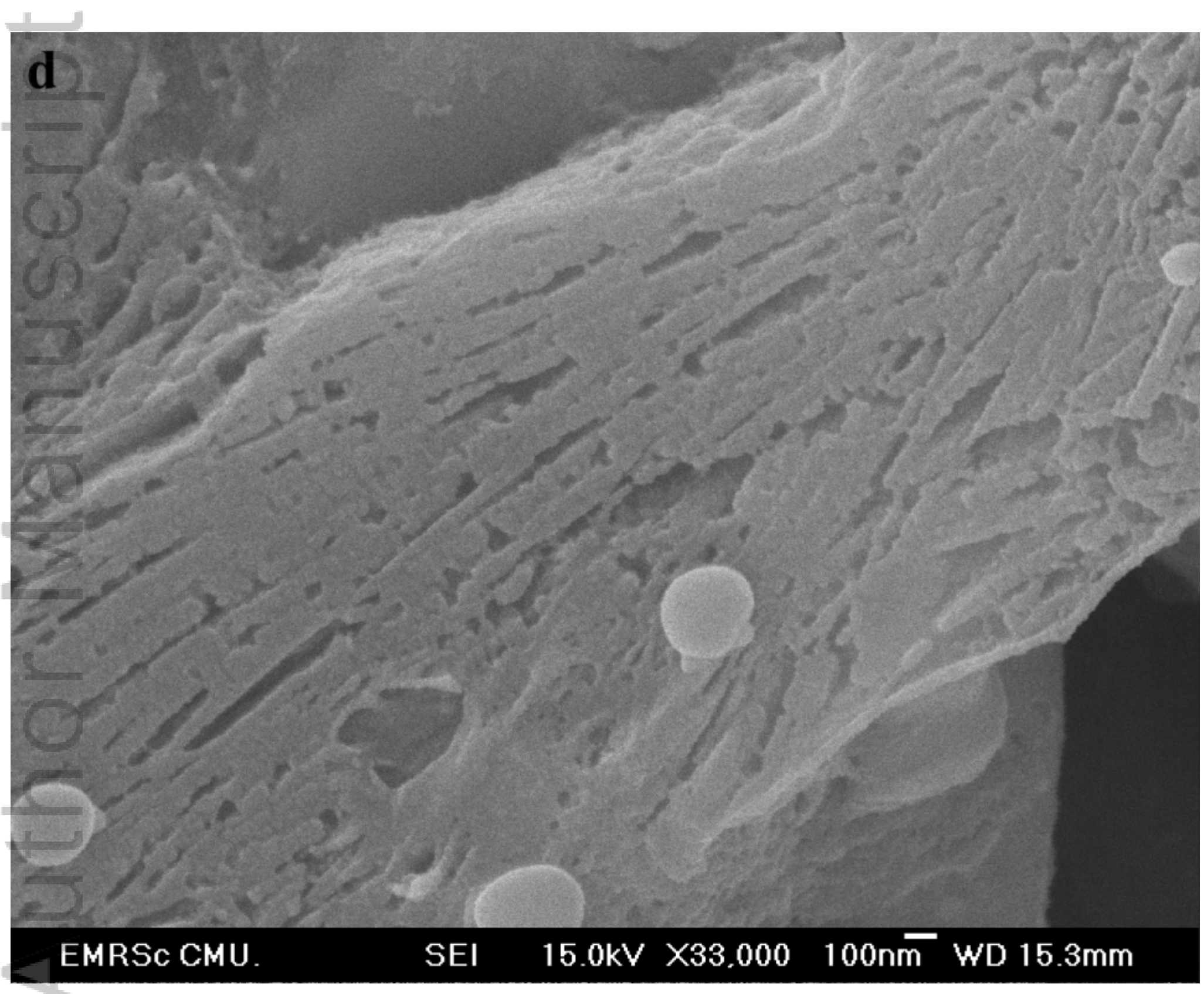

A0C_4747_f6d.tif

This article is protected by copyright. All rights reserved. 


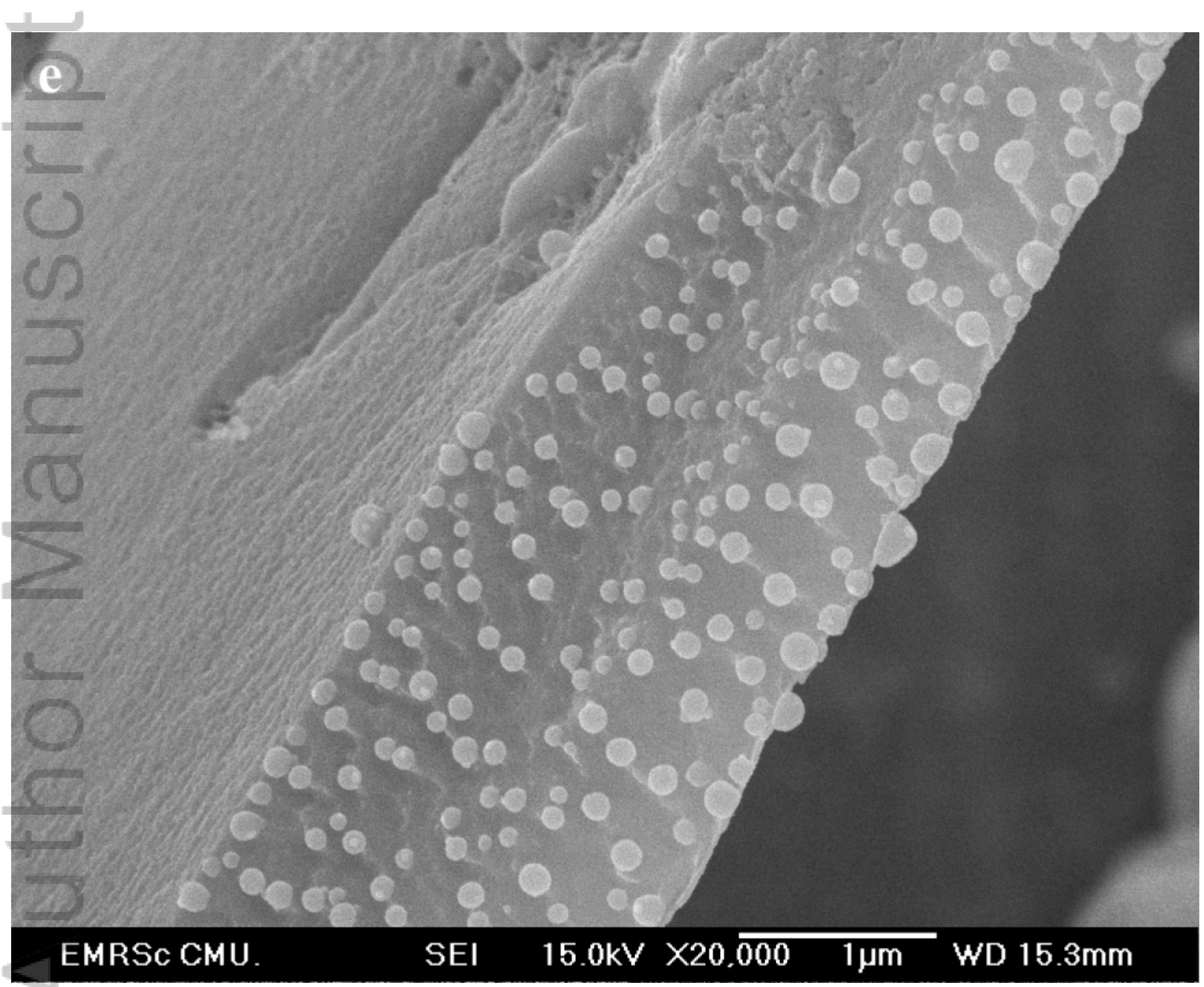

A0C_4747_f6e.tif

This article is protected by copyright. All rights reserved. 


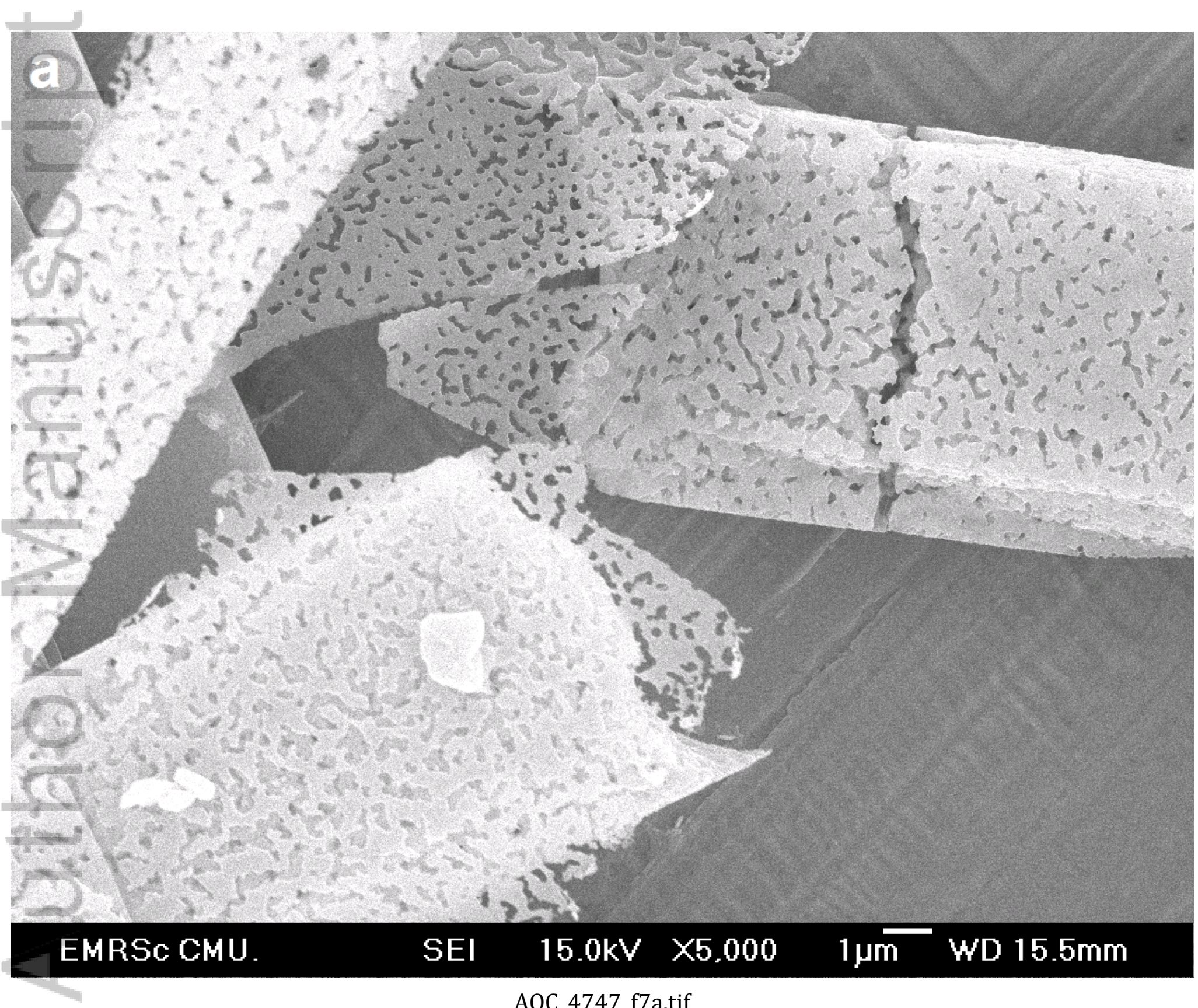

This article is protected by copyright. All rights reserved. 


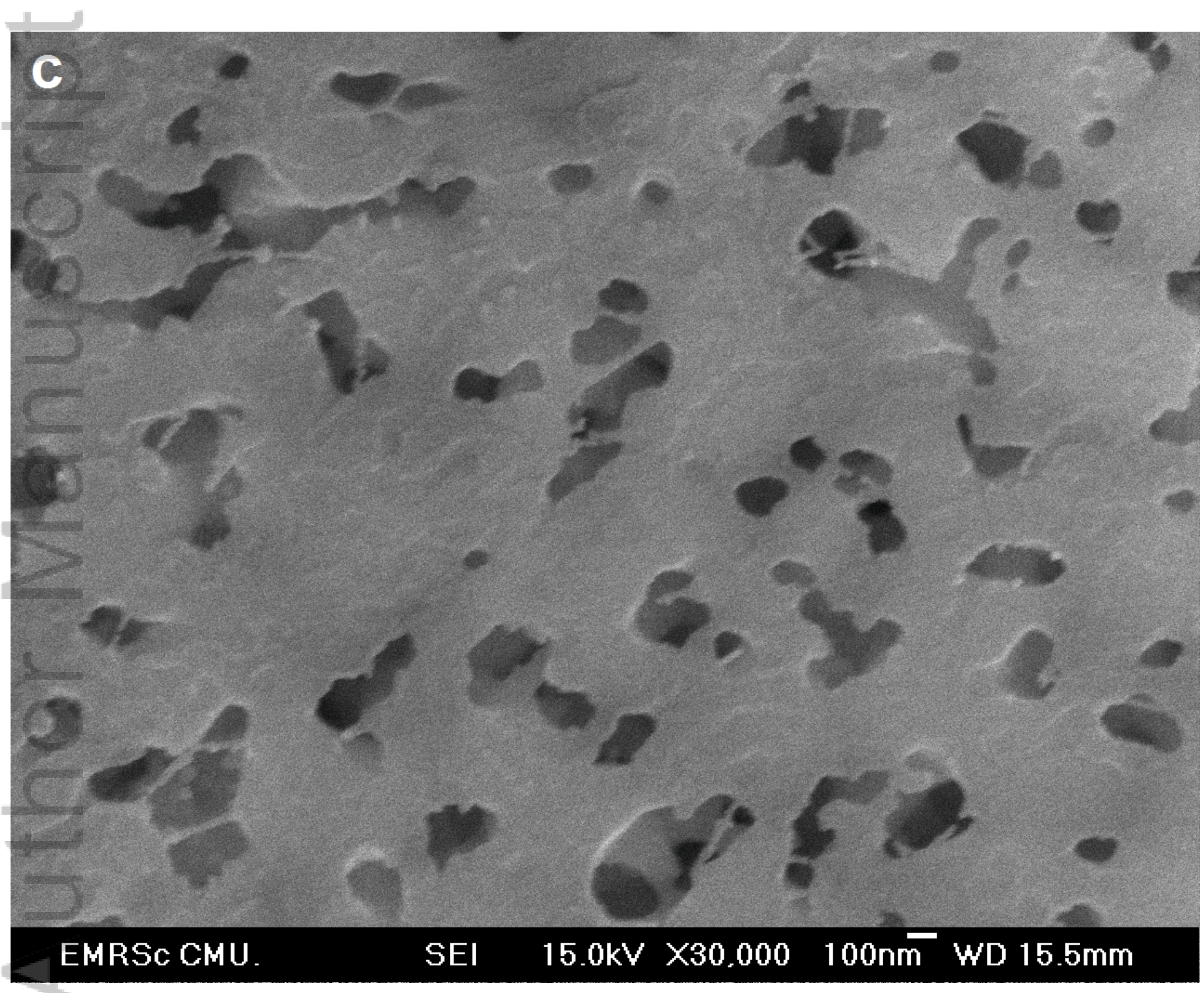

AOC_4747_f7c.tif

This article is protected by copyright. All rights reserved. 


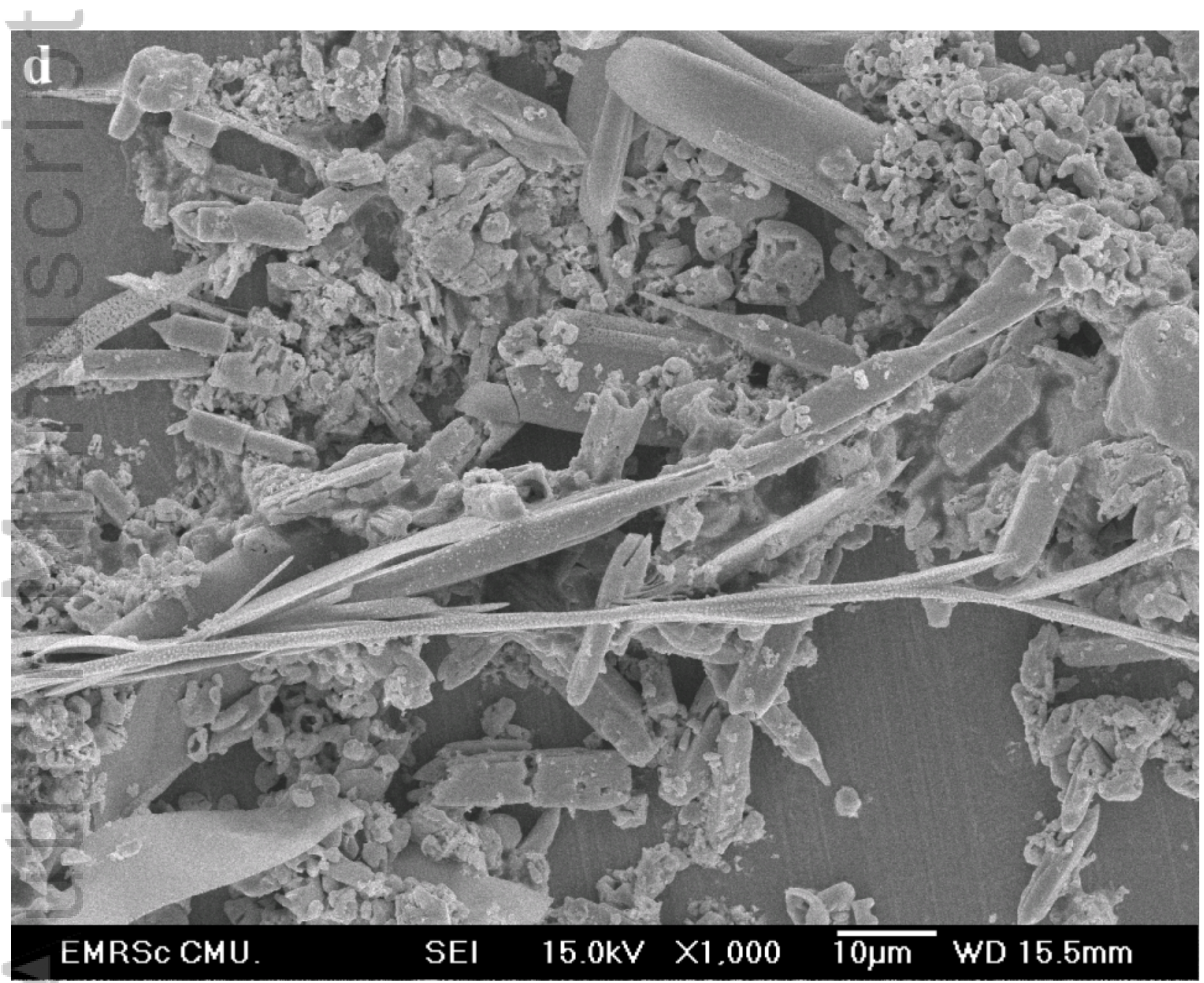

AOC_4747_f7d.tif

This article is protected by copyright. All rights reserved. 


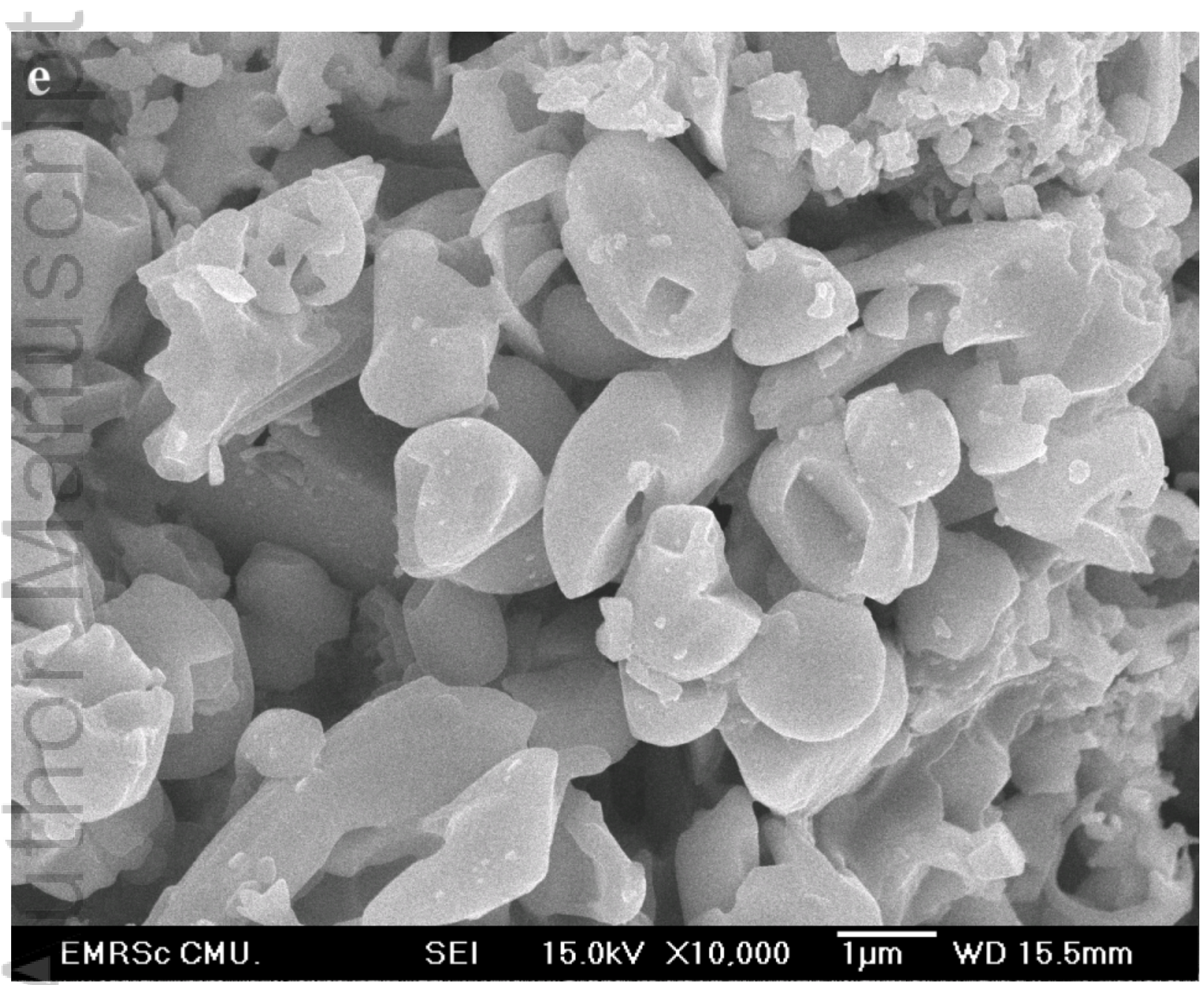

A0C_4747_f7e.tif

This article is protected by copyright. All rights reserved. 


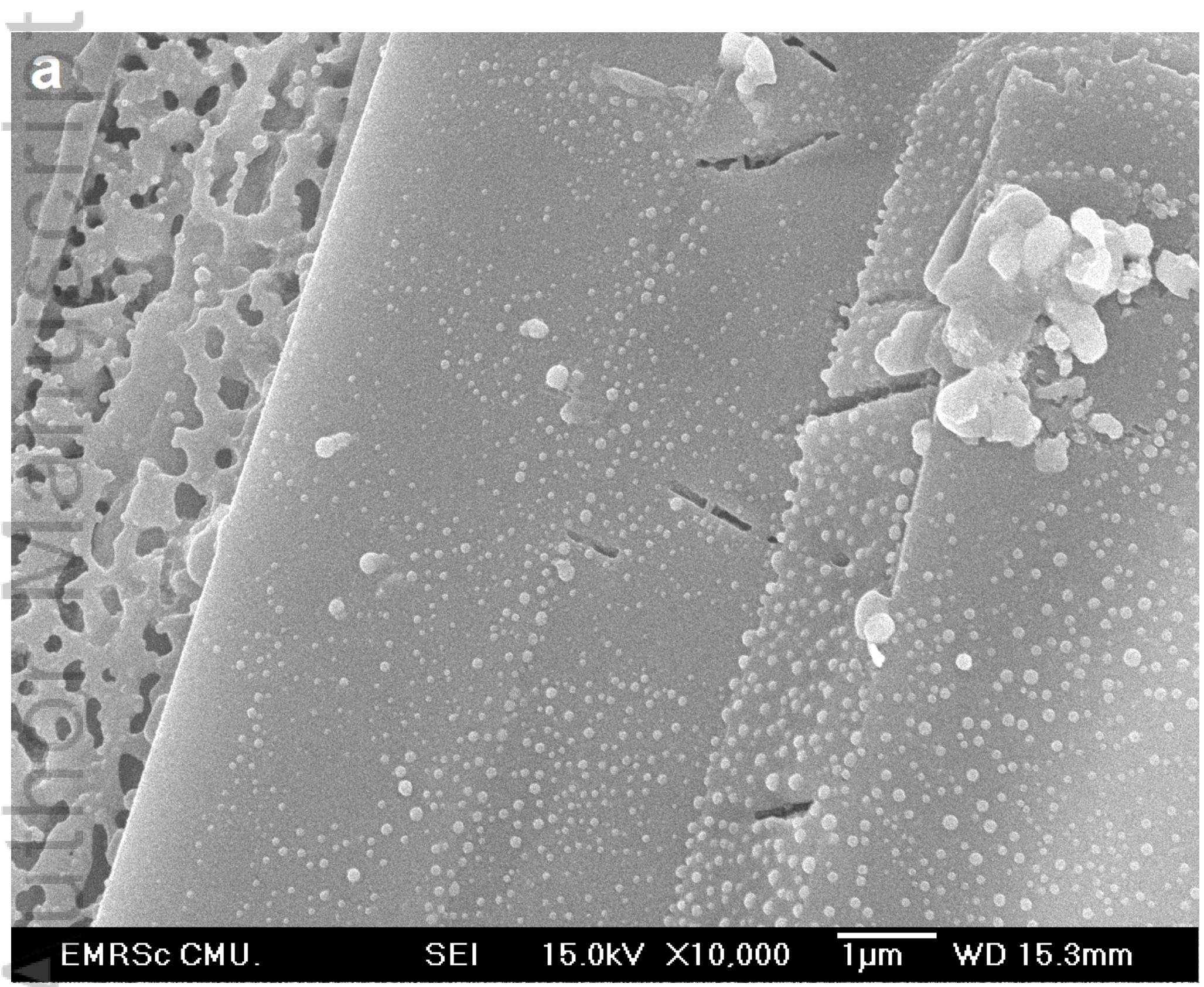

A0C_4747_f8a.tif

This article is protected by copyright. All rights reserved. 


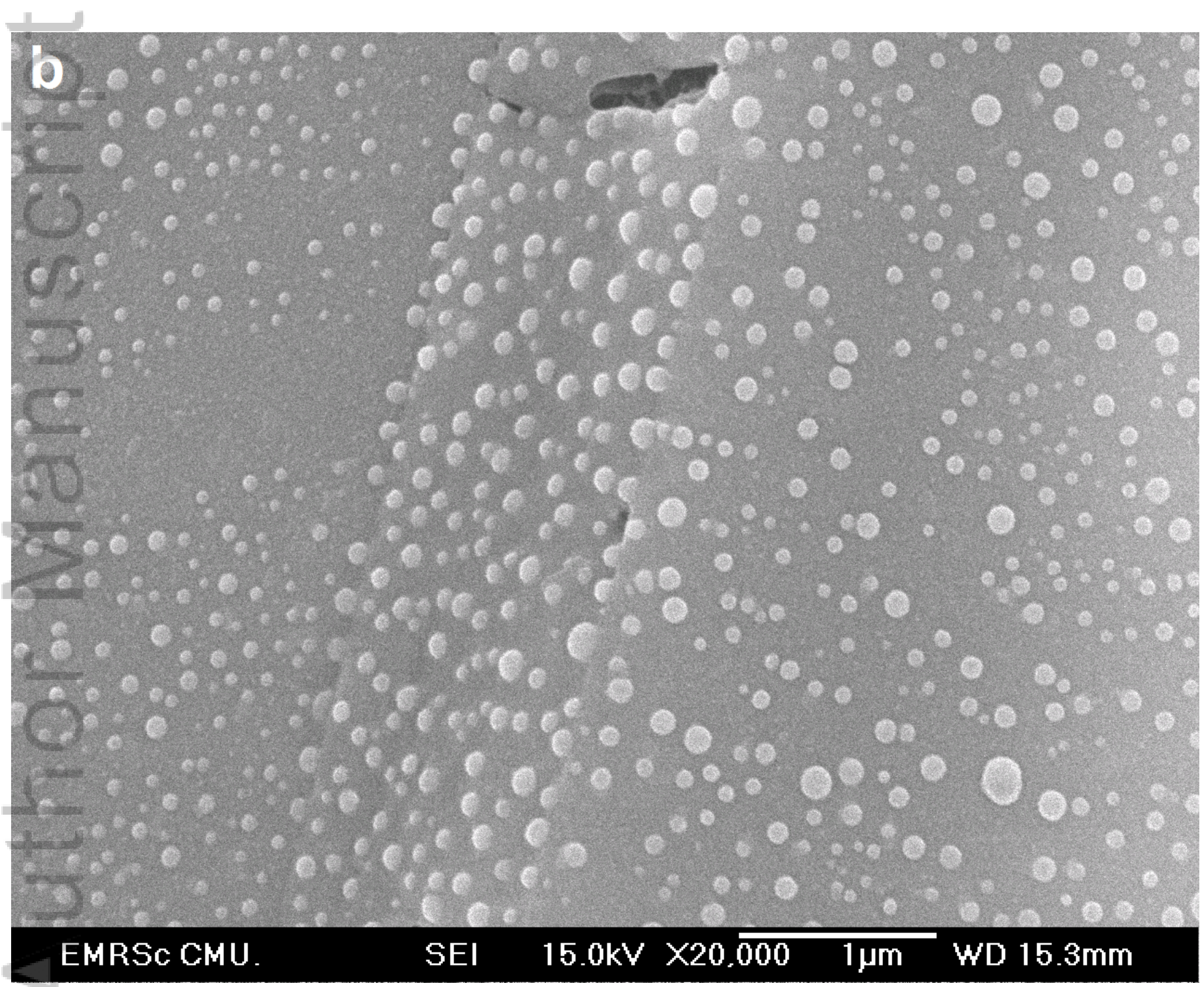

A0C_4747_f8b.tif

This article is protected by copyright. All rights reserved. 


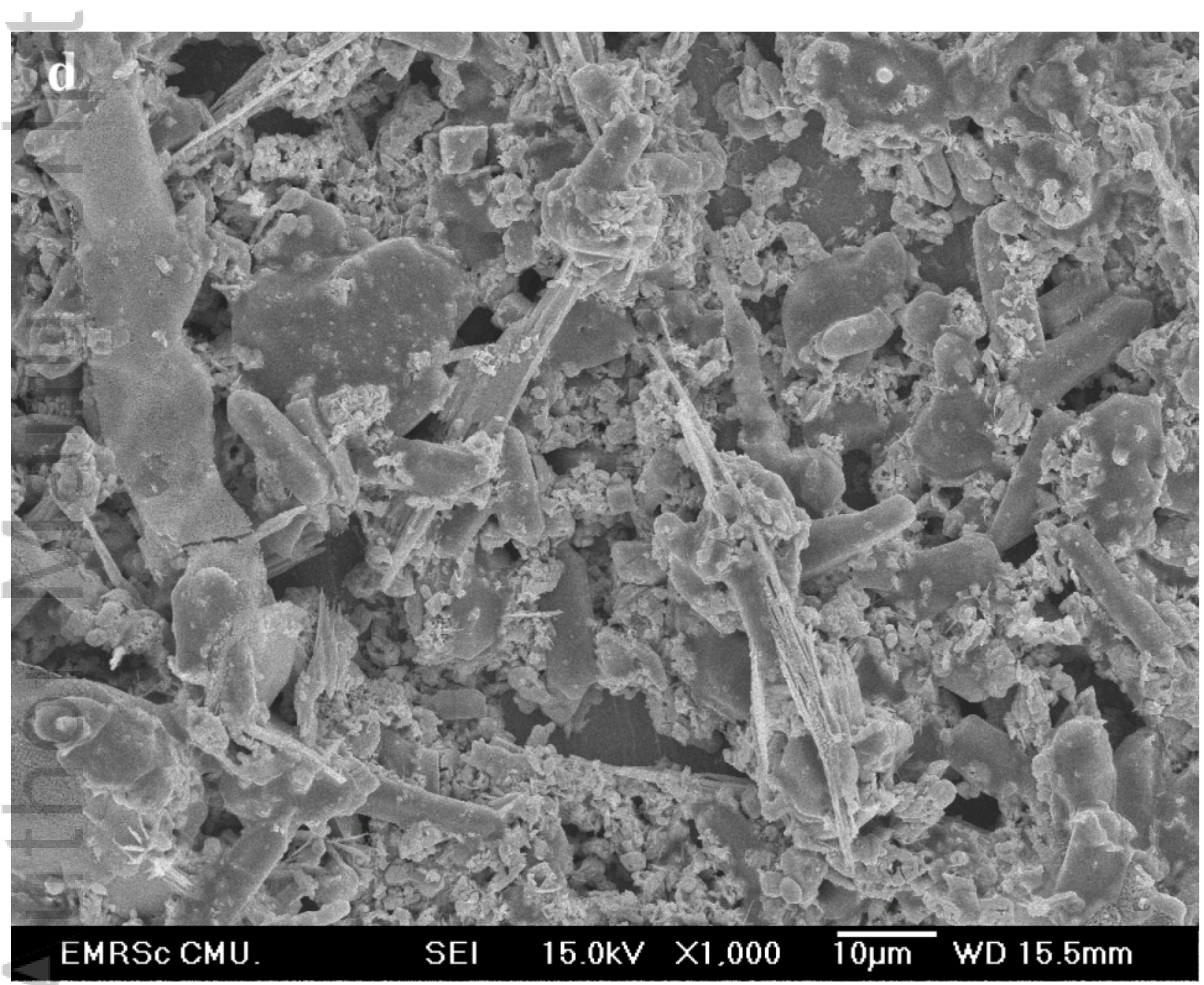

AOC_4747_f8d.tif

This article is protected by copyright. All rights reserved. 


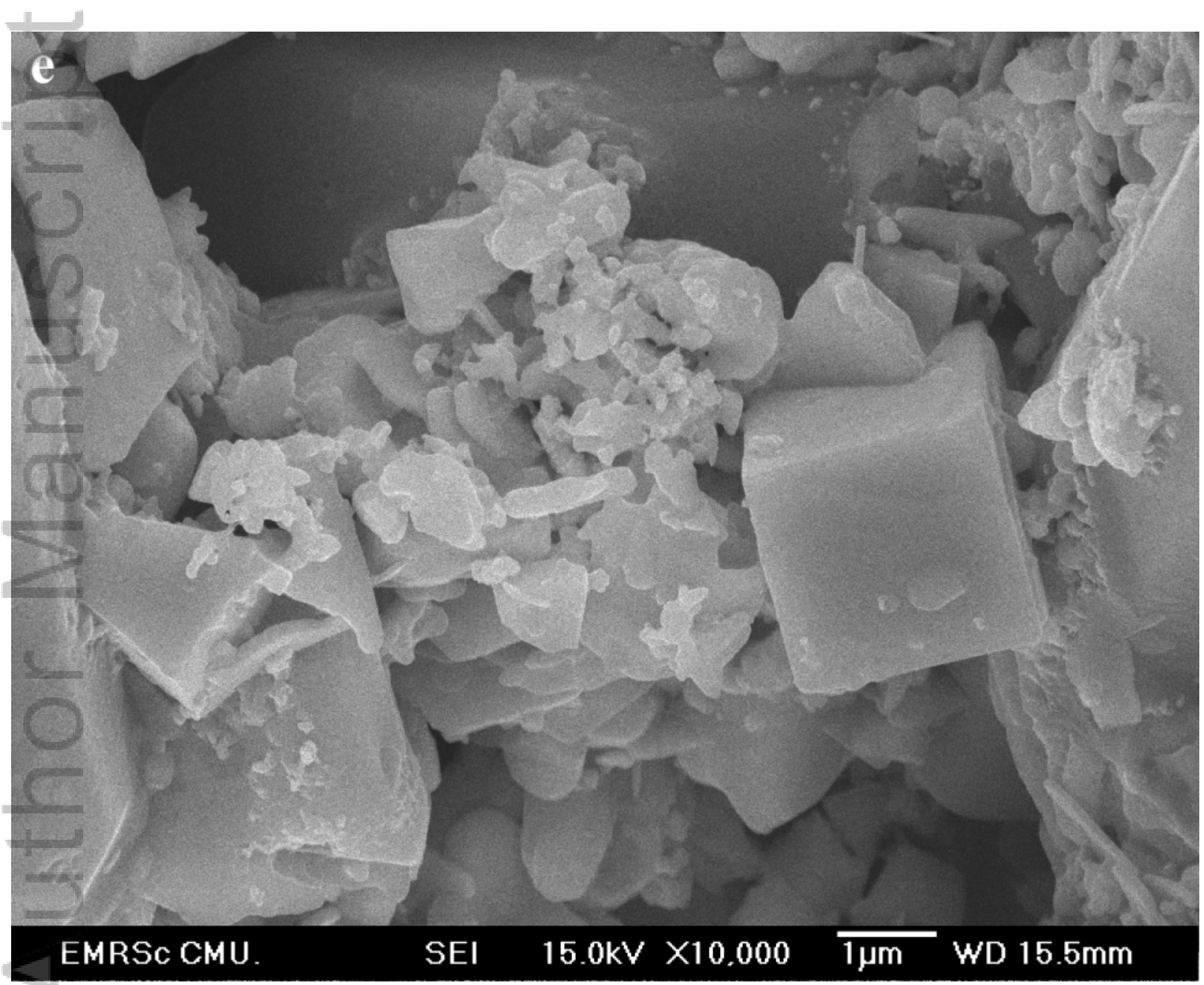

A0C_4747_f8e.tif

This article is protected by copyright. All rights reserved. 
